\title{
Mesoscale Convective Vortex Formation in a Weakly Sheared Moist Neutral Environment
}

\author{
RoBert J. CONZEMIUS \\ Department of Atmospheric Science, Colorado State University, Fort Collins, Colorado, and Windlogics, Inc., \\ Grand Rapids, Minnesota \\ Richard W. MOORE \\ Department of Atmospheric Science, Colorado State University, Fort Collins, Colorado, and Institute for Atmospheric and Climate \\ Science (IACETH), ETH-Zürich, Zurich, Switzerland

\section{Michael T. Montgomery} \\ Department of Atmospheric Science, Colorado State University, Fort Collins, Colorado, Department of Meteorology, \\ Naval Postgraduate School, Monterey, California, and Hurricane Research Division, NOAA/AOML, Miami, Florida \\ Christopher A. DAVIS \\ National Center for Atmospheric Research, Boulder, Colorado
}

(Manuscript received 31 January 2006, in final form 31 July 2006)

\begin{abstract}
Idealized simulations of a diabatic Rossby vortex (DRV) in an initially moist neutral baroclinic environment are performed using the fifth-generation National Center for Atmospheric Research-Pennsylvania State University (NCAR-PSU) Mesoscale Model (MM5). The primary objective is to test the hypothesis that the formation and maintenance of midlatitude warm-season mesoscale convective vortices (MCVs) are largely influenced by balanced flow dynamics associated with a vortex that interacts with weak vertical shear. As a part of this objective, the simulated DRV is placed within the context of the Bow Echo and Mesoscale Convective Vortex Experiment (BAMEX) field campaign by comparing its tangential velocity, radius of maximum winds, CAPE, and shear with the MCVs observed in BAMEX.

The simulations reveal two distinct scales of development. At the larger scale, the most rapidly growing moist baroclinic mode is excited, and exponential growth of this mode occurs during the simulation. Embedded within the large-scale baroclinic wave is a convective system exhibiting the characteristic DRV development, with a positive potential vorticity (PV) anomaly in the lower troposphere and a negative PV anomaly in the upper troposphere, and the positive/negative PV doublet tilted downshear with height. The DRV warm-air advection mechanism is active, and the resulting deep convection helps to reinforce the DRV against the deleterious effects of environmental shear, causing an eastward motion of the convective system as a whole.

The initial comparisons between the simulated DRVs and the BAMEX MCVs show that the simulated DRVs grew within background conditions of CAPE and shear similar to those observed for BAMEX MCVs and suggest that the same dynamical mechanisms are active. Because the BAMEX field campaign sampled MCVs in different backgrounds of CAPE and shear, the comparison also demonstrates the need to perform additional simulations to explore these different CAPE and shear regimes and to understand their impacts on the intensity and longevity of MCVs. Such a study has the additional benefit of placing $\mathrm{MCV}$ dynamics in an appropriate context for exploring their relevance to tropical cyclone formation.
\end{abstract}

\section{Introduction}

Moist, diabatic processes have long been known to play a role in atmospheric disturbances of many scales,

Corresponding author address: Robert Conzemius, Windlogics Inc., 201 NW 4th Street, Grand Rapids, MN 55744.

E-mail: Robert.conzemius@att.net ranging from the large, extratropical wintertime cyclones to supercell thunderstorms. The influence of diabatic processes on the former was first proposed by Eady (1949) in his seminal paper on baroclinic instability in which he hypothesized that the effect of latent heat release in clouds was simply to reduce the static stability. Later studies (Raymond and Jiang 1990, hereafter RJ90; Montgomery and Farrell 1991, 1992; Snyder

DOI: $10.1175 / J A S 3898.1$

(C) 2007 American Meteorological Society 
and Lindzen 1991; Fantini and Buzzi 1994, 1997; Mak 1994; Whitaker and Davis 1994; Fantini 1995; Parker and Thorpe 1995; Moore and Montgomery 2004, hereafter MM04; Lapeyre and Held 2004; Moore and Montgomery 2005, hereafter MM05) incorporated the effects of moisture more directly and found the dynamics of moist, baroclinic disturbances to be governed by two growth regimes occurring at different scales. At long wave scales, dry dynamics dominated, and the structure was qualitatively similar to dry baroclinic waves. At short scales, a different structure emerged, which had no dry counterpart. Because of their differences from dry baroclinic systems, the moist disturbances have been described as diabatic Rossby waves (Parker and Thorpe 1995). Because of their three-dimensional vortical structure in most cases, MM04 and MM05 coined the term diabatic Rossby vortices (DRVs).

Moist processes are certainly critical to the dynamics of warm season midlatitude disturbances, such as mesoscale convective systems (MCSs; Houze 2004). Many MCSs develop a mesoscale convective vortex (MCV) on their poleward end, and these MCVs have been associated with the longevity and maintenance of MCSs (Davis et al. 2004; Houze 2004). Because DRVs and MCVs are both cyclonic in nature and driven heavily by diabatic processes, it might be expected that they have a common dynamical link. However, such a link has not been completely established. One of the objectives of the current paper is to assess the hypothesized link between the dynamics of the DRV and MCV.

RJ90, Snyder and Lindzen (1991), and Parker and Thorpe (1995) described the growth of baroclinic modes that exhibit the behavior of diabatic Rossby waves. These waves exhibit a structure and a propagation and amplification mechanism that can be traced to the diabatic generation of potential vorticity (PV) in a manner analogous to the way that Rossby waves owe their existence to the meridional advection of planetary vorticity. MM04 and MM05 described the structures arising during the early stages of development of midlatitude maritime extratropical cyclones as DRVs (DRVs can occur at other stages as well), which are essentially governed by the same dynamics but exhibit a closed contour of potential vorticity (PV). The DRV has a vertical dipole structure that consists of a lowerto midtropospheric maximum in $\mathrm{PV}$, overlain by a relative minimum in PV, with the entire structure tilted slightly downshear with height. MM04 showed, using a model similar to that of Whitaker and Davis (1994), that the growth modes of moist baroclinic systems do not exhibit the same short wave cutoff found for dry baroclinic modes, but rather, for the inviscid case, the growth rate becomes nearly independent of wavenumber as wavenumber increases. For this reason, the DRV growth mechanism may be relevant for subsynoptic midlatitude systems such as MCVs.

The growth and maintenance of a DRV occur via an interaction between the balanced motions of the vortex and the weak baroclinic zone in which the vortex resides. The resultant lifting and associated diabatic heating on the downshear side of the vortex helps reinforce the vertical dipole structure against the shear that is associated with the baroclinic environment. Recent work has shown this type of growth mechanism to be quite robust. Building off of Montgomery and Farrell (1992), MM04 and MM05 conducted numerous idealized model simulations (using both a simplified balance model and a full-physics mesoscale model) to describe and better understand the mechanism in a moist, baroclinic wintertime environment. These coherent structures have been shown to play a role in such varied atmospheric processes as explosive cyclogenesis (Gyakum et al. 1992; Wernli et al. 2002), squall lines (Parker and Thorpe 1995), and polar lows (Montgomery and Farrell 1991, 1992; Fantini and Buzzi 1993; Mak 1994). The present study seeks to extend the MM05 investigation of the DRV dynamics into convectively less stable environments. Beginning with an initially moist adiabatic environment, CAPE develops as a result of warm advection due to the balanced dynamics of the vortex. In such convectively unstable environments, one would expect the DRV dynamics to be more heavily influenced by diabatic effects, but we will demonstrate that the DRV concept remains pertinent for the MCV dynamics considered here.

Evidence of a DRV-like mechanism for MCVs has existed for some time. Numerous studies of MCVs (Cotton et al. 1989; Menard and Fritsch 1989; RJ90; Davis and Weisman 1994; Fritsch et al. 1994; Jiang and Raymond 1995, hereafter JR95; Olsson and Cotton 1997b; Trier et al. 2000a,b; Davis and Trier 2002; Trier and Davis 2002; Knievel et al. 2004) have mentioned at least one aspect of the DRV mechanism outlined above. In particular, RJ90 were the first to propose a theory for long-lived MCSs based on the interaction of a balanced midlevel vortex and a moist baroclinic environment. Their theory elucidates how a preexisting, midlevel cyclonic circulation can (i) induce a mesoscale ascending flow in a vertically sheared environment, (ii) trigger deep convection, and (iii) through diabatic and advective PV processes, further intensify the initial midlevel circulation. In this way, it describes a selfsustaining process for vortex maintenance, given a conducive environment. In the present study, we wish to 
build upon the foundation laid by RJ90 and the follow up study of JR95. In both of these studies, a nonlinear balance constraint was incorporated, forcing the use of assumptions regarding the direct effects of convective processes. In the present study, we relax these constraints to determine if this is indeed the basic mechanism at work when convection is represented explicitly. While RJ90 and JR95 proposed this mechanism for the maintenance of long-lived MCVs, we demonstrate here that this mechanism can also generate MCVs.

The ultimate test of theories and simulations is to compare them against observational data. The second objective of this study is to perform an initial comparison between the numerical simulations contained herein with atmospheric data from the recent Bow Echo and MCV Experiment (BAMEX; Davis et al. 2004), which has provided a wealth of data on MCSs and MCVs. Specifically, we will compare the background CAPE and shear and the maximum tangential velocity and radius of maximum winds of the simulated DRVs with those of the MCVs in BAMEX. Such a comparison of vortex parameters should yield clues to assess whether the same DRV processes are present in both cases. Although the comparison is not comprehensive, it will lay the groundwork for upcoming observational and modeling studies exploring the dynamics of MCVs in environments of different CAPE and shear.

To achieve the objectives outlined above, several numerical experiments have been conducted. These experiments are discussed in the following sections.

\section{Experimental design}

The fifth-generation National Center for Atmospheric Research-Pennsylvania State University (NCAR-PSU) Mesoscale Model (MM5) is a limitedarea, nonhydrostatic, terrain-following sigmacoordinate numerical model. Grell et al. (1994) provide a complete description of MM5. The following choices are used for the simulation: a domain size of approximately $12000 \mathrm{~km} \times 5000 \mathrm{~km}$ in the zonal and meridional directions, respectively; 23 vertical levels; full Coriolis force; and the simple ice (Dudhia) moisture scheme. The lateral boundary condition for all runs is that of the basic-state environment. Additionally, so as to focus on the DRV formation, intensification and maintenance process, we will neglect surface fluxes of latent and sensible heat as well as radiative processes.

An idealized initial condition is used. It is comprised of a low-level, warm-core vortex embedded in a moist, baroclinic zone over a flat land surface. This initial condition is designed to avoid preconditioning the interior troposphere with PV anomalies, yet still allows the gen- eration of interior PV anomalies later in the numerical experiment.

\section{a. Basic state}

The idealized basic-state environment consists of a zonally homogeneous, vertical wind shear in thermal wind balance with a meridionally varying temperature gradient. Three further constraints are imposed: (i) a linearly increasing zonal wind with height in the troposphere (which allows for a more direct comparison with the MCV and DRV work of RJ90 and MM05, respectively), (ii) an atmospheric vertical temperature profile that is neutral to moist ascent of boundary layer parcels (i.e., moist neutral), and (iii) a well-mixed boundary layer. It should be emphasized; only the initial, unperturbed basic-state environment is precisely moist neutral. Once meridional motion ensues, CAPE can be and is generated, reaching values up to $600 \mathrm{~J} \mathrm{~kg}^{-1}$.

The construction of the basic state begins by imposing a surface temperature gradient as follows:

$$
\Delta \bar{\Theta}_{\mathrm{sfc}}(y)=-\left[g^{-1} \theta_{o} f S(y) \Delta y\right]
$$

where $g$ is the gravitational acceleration; $\theta_{\mathrm{o}}$ is the reference surface potential temperature (294 K); $f$ is the Coriolis parameter $(2 \Omega \sin \phi) ; S(y)$ is a first-guess, meridionally varying shear parameter; and $\Delta y$ is the grid increment in the meridional direction. The function $S(y)$ is the upper half of a sine wave, which reaches a maximum of $1.5 \mathrm{~m} \mathrm{~s}^{-1} \mathrm{~km}^{-1}$ (a value half that of the Eady basic-state shear) at $45^{\circ} \mathrm{N}$ and decreases to 0 $\mathrm{m} \mathrm{s}^{-1} \mathrm{~km}^{-1}$ at $15^{\circ}$ and $75^{\circ} \mathrm{N}$. At the center of the baroclinic zone $\left(45^{\circ} \mathrm{N}\right)$, the surface temperature is $293 \mathrm{~K}$. In practice, (1) is implemented on an equal-angle, latitude-pseudoheight grid, assuming the shear parameter is constant over one meridional grid increment (approximately $56 \mathrm{~km}$ ). The winds are then calculated using the surface temperature gradient (1), geostrophic and hydrostatic balance, and zero pressure gradient at the surface. The goal is a linearly increasing wind with height with the maximum shear found at the center of the baroclinic zone $\left(45^{\circ} \mathrm{N}\right)$.

In a baroclinic, moist neutral environment, the temperature lapse rate would have a latitudinal dependence if the lifting condensation level (LCL) height were constant in the domain. Such dependence is undesirable if height-constant shear is intended. To reduce this effect, a meridionally varying LCL is introduced (Fig. 1a). By allowing the LCL height to decrease as one progresses northward through the baroclinic zone, it is possible to approximate a constant meridional temperature gradient with height and hence, through thermal wind balance, a linearly increasing 
a

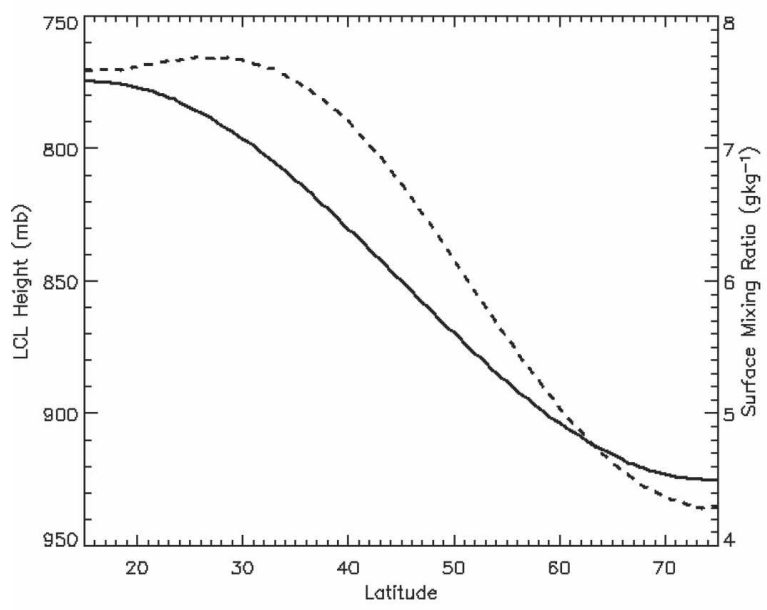

b

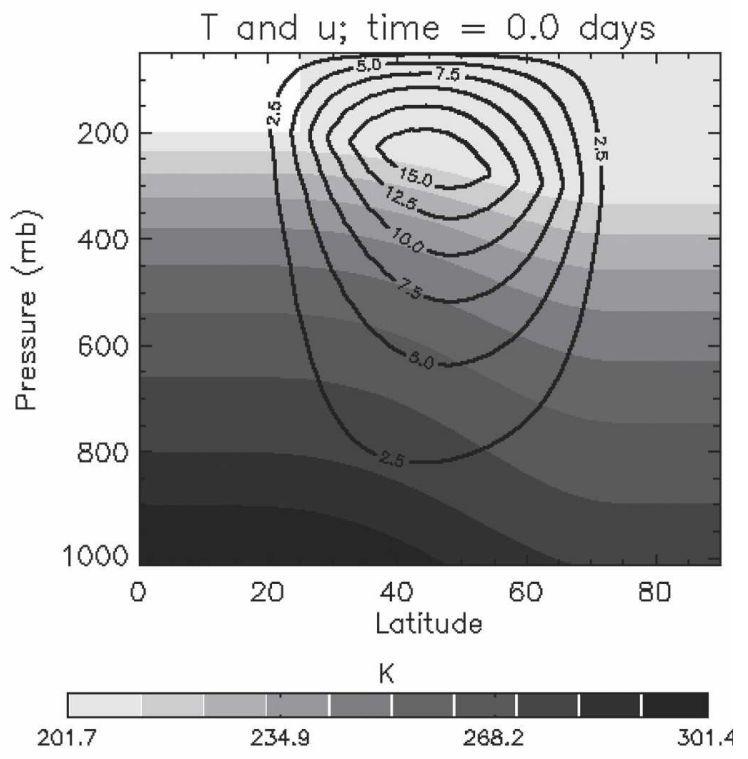

c

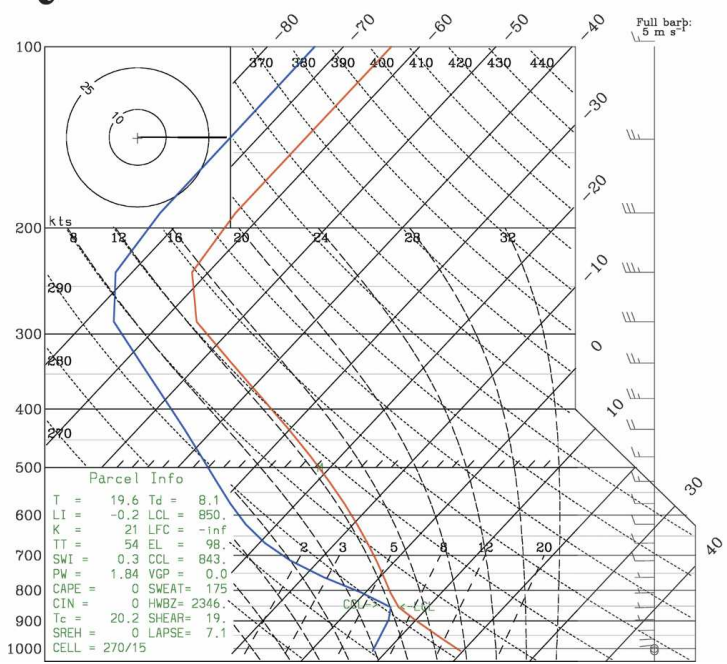

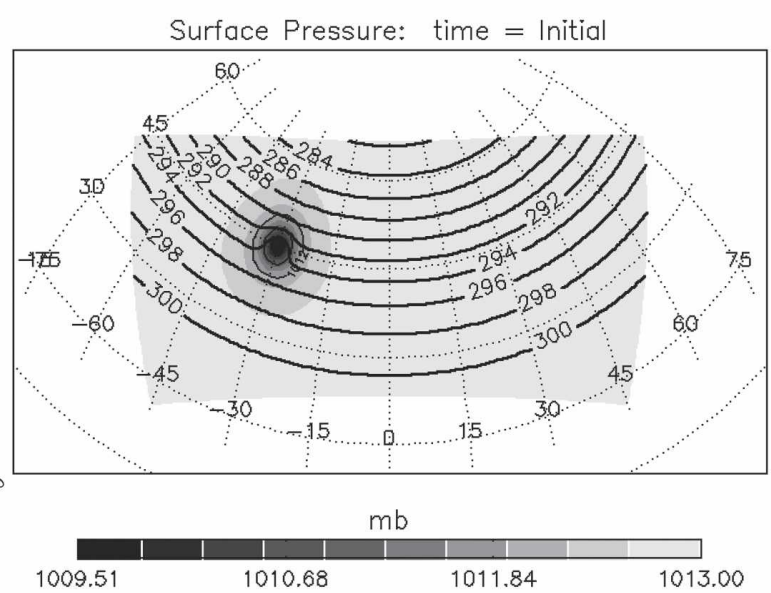

FIG. 1. The basic-state environment: (a) the meridional variation of the lifting condensation level (mb; solid line) and the surface mixing ratio ( $\mathrm{g} \mathrm{kg}^{-1}$; dashed line); (b) latitude-pressure cross section of temperature ( $\mathrm{K}$; shading) and zonal wind (black contour lines; interval is $2.5 \mathrm{~m} \mathrm{~s}^{-1}$ ); (c) skew $T$ - $\log p$ diagram at $45^{\circ} \mathrm{N}$; and (d) the surface pressure (mb; shading) and temperature (black contour lines; interval is $2 \mathrm{~K}$ ).

zonal wind with height. Given the LCL height, constraint (iii) establishes the surface moisture field. The result is a gradient of absolute surface moisture, decreasing from south to north (Fig. 1a).

Once the LCL height and surface moisture field are established, it is straightforward to calculate a moist neutral temperature profile for a given surface temperature and LCL height: below (above) the LCL, the potential temperature (equivalent potential temperature) is conserved. The result is a vertical atmospheric profile that is neutral to the lifting of a surface parcel of air. The actual zonal wind field is subsequently recovered by enforcing thermal wind balance (Fig. 1b).

Above the LCL, the moisture field is defined by a domain-constant relative humidity profile. It takes the form of one-half of a hyperbolic tangent, decreasing from saturation at the LCL to a constant value of $25 \%$ above $400 \mathrm{mb}$. The resulting skew- $T$ diagram at $45^{\circ} \mathrm{N}$ is presented in Fig. 1c.

While the method to construct the basic state is 
rather ad hoc in comparison with the more stringent constraint of zero equivalent potential vorticity (in the case of a moist symmetrically neutral atmosphere; e.g., Fantini 2004), it is chosen here for its simplicity and the ease with which the stability of the atmosphere can be altered.

\section{b. Initial vortex}

As in MM05, a perturbation low-level, warm core vortex is superimposed upon the basic state. For a detailed description of the construction of the perturbation vortex, see the appendix in MM05. A positive 3-K perturbation of the potential temperature is assumed along the lower boundary. The potential temperature perturbation decays horizontally from the center of the vortex in the form of a Gaussian distribution (e-folding radius of $300 \mathrm{~km}$ ) and exponentially with psuedoheight in the vertical. The perturbation wind field is recovered from the perturbation geopotential field, incorporating the constraints of zero quasigeostrophic potential vorticity in the interior and geostrophic balance. The resulting surface pressure field is shown in Fig. 1d.

It may seem at first that the introduction of a vortex into the initial state may artificially predispose the simulation toward the development of a DRV/MCV. However, the initial vortex has zero perturbation PV in its interior, and it is also well documented (see, e.g., Davis and Weisman 1994; Weisman and Davis 1998) that idealized simulations of deep convection, initiated using the warm bubble approach, spontaneously produce MCV-like vortices without such an initial vortex. Thus, the DRV/MCV that develops in the simulation can be regarded as one that naturally develops from the convection and its associated diabatic heating.

\section{c. Simulation grid}

As one of the main goals of this work is to examine the effect of convective processes on disturbance formation and growth, we have chosen to explicitly represent convection. To do so, four domains of varying horizontal grid interval are used $(90,30,10$, and $3.3 \mathrm{~km})$. A 10 -day simulation on a $90-\mathrm{km}$ grid, incorporating the Grell et al. (1994) cumulus parameterization, is used to establish the onset of deep convection (shortly after day 5). For the simulation, therefore, the three nested grids are initiated at day 5 and are used over the subsequent $72 \mathrm{~h}$, a period of time that encompasses convective organization and the formation and intensification of a midlevel, cyclonic circulation. The intermediate resolution domains (also incorporating the Grell cumulus parameterization) do not move over this time period; however, to ensure the cloud-representing $3.3-\mathrm{km}$ grid
TABLE 1. List of simulations.

\begin{tabular}{ll}
\hline \hline Simulation & \multicolumn{1}{c}{ Description } \\
\hline $\begin{array}{l}\text { Control } \\
\text { Isolated }\end{array}$ & $\begin{array}{l}\text { Control run } \\
\text { Initial vortex radial profile is second derivative } \\
\text { of Gaussian }\end{array}$ \\
Dry & $\begin{array}{l}\text { Latent heating turned off at } t=134.4 \mathrm{~h} \\
\text { CAPE }\end{array}$ \\
\hline
\end{tabular}

encompasses the region of deep convection, this innermost domain is moved twice during the 72-h time period at an interval of $24 \mathrm{~h}$. The described run represents the control simulation.

\section{d. Additional cases}

Three other simulations are conducted. They are listed in Table 1 and described here. The first of these is a dry run, intended to explore the role of convection in maintaining the vortex. This simulation is the same as in the control simulation, but the latent heating is turned off at $t=134.4 \mathrm{~h}$, when the MCV is considered to be fully developed. The results of this dry run are discussed in section $3 b(2)$.

The second supplementary simulation is intended to explore the effects of the initial vortex shape on the ensuing disturbance and, rather than using the Gaussian-shaped surface temperature perturbation, begins with a profile represented by the second derivative of the Gaussian profile (Fig. 2). The results of this second sensitivity simulation are presented in section $3 \mathrm{~d}$.

Finally, a simulation with CAPE of approximately $2400 \mathrm{~J} \mathrm{~kg}^{-1}$ in the vicinity of the initial vortex, is conducted. The CAPE simulation will be more fully analyzed in a later study. Within the context of the present study (which seeks to assess the dynamical link between DRVs and MCVs), its purpose is to extend the parameter space into the range of atmospheric conditions typically associated with MCVs.

\section{e. Energy conversion calculations}

To estimate the relative contributions to the vortex intensification from diabatic and baroclinic processes, the diabatic $\left(G_{E}\right)$ and baroclinic $\left(C_{A}\right)$ conversion terms were calculated as in MM05. These conversion terms represent the diabatic conversion of latent heat energy and the baroclinic conversion of mean state available potential energy (APE), respectively, to eddy APE. The terms are defined by the following formulas (Norquist et al. 1977):

$$
G_{E}=\int_{p_{1}}^{p_{2}} \frac{\overline{Q^{\prime} T^{\prime}}}{c_{p} \bar{\sigma}} d p,
$$



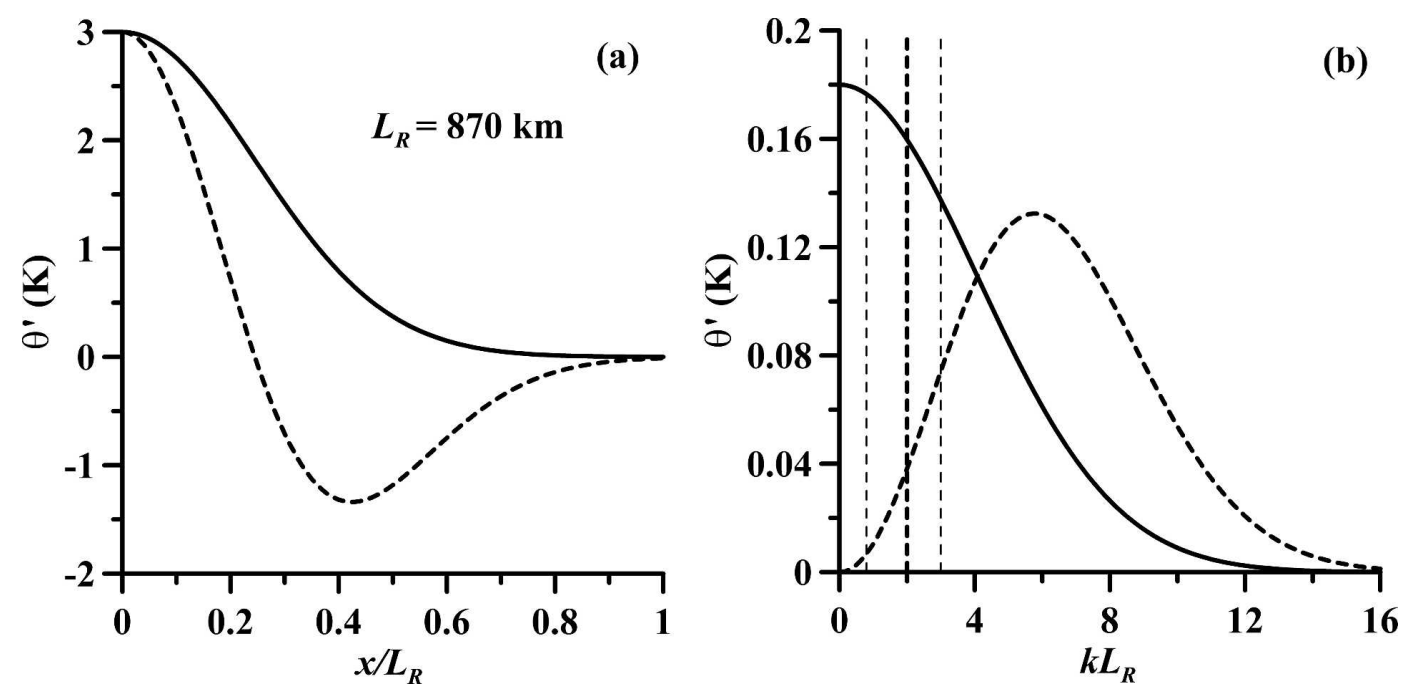

FIG. 2. Radial profiles of the initial potential temperature distribution at the surface for the initial vortex in the control simulation (solid lines) and in the simulation with the isolated radial profile (dashed lines): (a) physical space and (b) Fourier space. In (b), the lighter vertical dashed lines correspond to the region in which the growth rate is dependent on wavenumber (moist baroclinic modes), and the heavy vertical dashed line corresponds to the most rapidly growing mode.

$$
C_{A}=-\int_{p_{1}}^{p_{2}} \frac{\overline{\left[v^{\prime} T^{\prime}\right]}}{\bar{\sigma}} \frac{\partial[T]}{\partial y} d p-\int_{p_{1}}^{p_{2}} \frac{\overline{\left[\omega^{\prime} T^{\prime}\right]}}{\bar{\sigma}} \frac{\partial[T]^{*}}{\partial p} d p
$$

where $[(\cdot)]$ represents a zonal average of the quantity $(\cdot)$ and $\overline{[(\cdot)]}$ represents an area mean. A prime indicates the deviation from the zonal average, and an asterisk indicates a deviation of the zonal average from the area mean. The variable $Q$ is the diabatic heating rate $(\mathrm{J}$ $\left.\mathrm{kg}^{-1} \mathrm{~s}^{-1}\right), T$ is temperature, $c_{p}$ is the heat capacity at constant pressure for dry air $\left(\mathrm{J} \mathrm{kg}^{-1} \mathrm{~K}^{-1}\right), \sigma$ is the static stability

$$
\sigma=g\left(\frac{T}{c_{p}}-\frac{p}{R} \frac{\partial T}{\partial p}\right),
$$

$v$ is the meridional component of velocity, $\omega$ is the vertical velocity in pressure coordinates, and $p_{1}$ and $p_{2}$ are the pressure limits of integration.

Because the simulations are limited area simulations, a limited area analysis, encompassing the entire MCS structure, had to be performed. The area chosen for the analysis was centered on the surface pressure minimum on the $90-\mathrm{km}$ domain and extended 15 grid points (approximately $1350 \mathrm{~km}$ ) east and west of the minimum and 10 grid points (approximately $900 \mathrm{~km}$ ) north and south of the minimum. The resulting area of analysis was approximately $2700 \mathrm{~km}$ by $1800 \mathrm{~km}$. The analysis was performed on the $90-\mathrm{km}$ domain because the finer grids, particularly the $3.3-\mathrm{km}$ grid, did not always fully encompass the mesoscale convective system.

\section{Formation and maintenance of the midlevel cyclonic circulation}

The goals of this section are to illustrate, through the analysis of the idealized, cloud-representing mesoscale model simulations, that deep convection in a nearly moist neutral environment with moderate, deep vertical shear can spawn a disturbance with the characteristic structure and dynamics of a DRV. This is accomplished using the control simulation results, as well as comparisons between the control simulation and the sensitivity simulations (section $2 \mathrm{~d}$ ).

\section{a. General overview}

The development and evolution of the simulated disturbance is influenced by processes occurring on two different spatial scales. On the larger scale, a moist baroclinic mode is excited, and this disturbance grows exponentially during the simulation on a time scale of several days. The most noticeable growth occurs after $t=168 \mathrm{~h}$. The characteristics and importance of this larger scale growth will be further discussed in sections $3 c$ and $3 d$. Embedded within this large-scale (wavelength of approximately $2700 \mathrm{~km}$ ) baroclinic wave, a mesoscale disturbance forms, with a majority of the growth occurring on a shorter (approximate $12 \mathrm{~h}$ ) time scale. Because of the development of positive CAPE downshear from the mesoscale disturbance, the presence of a cold pool beneath it, and new convective cells developing at the leading edge of the cold pool, we will 


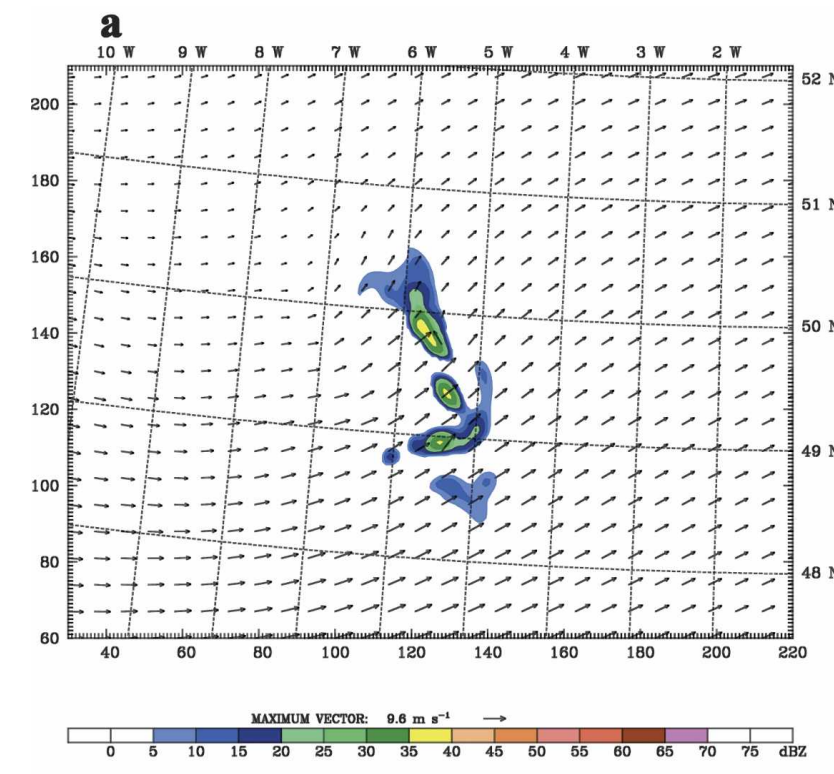

b
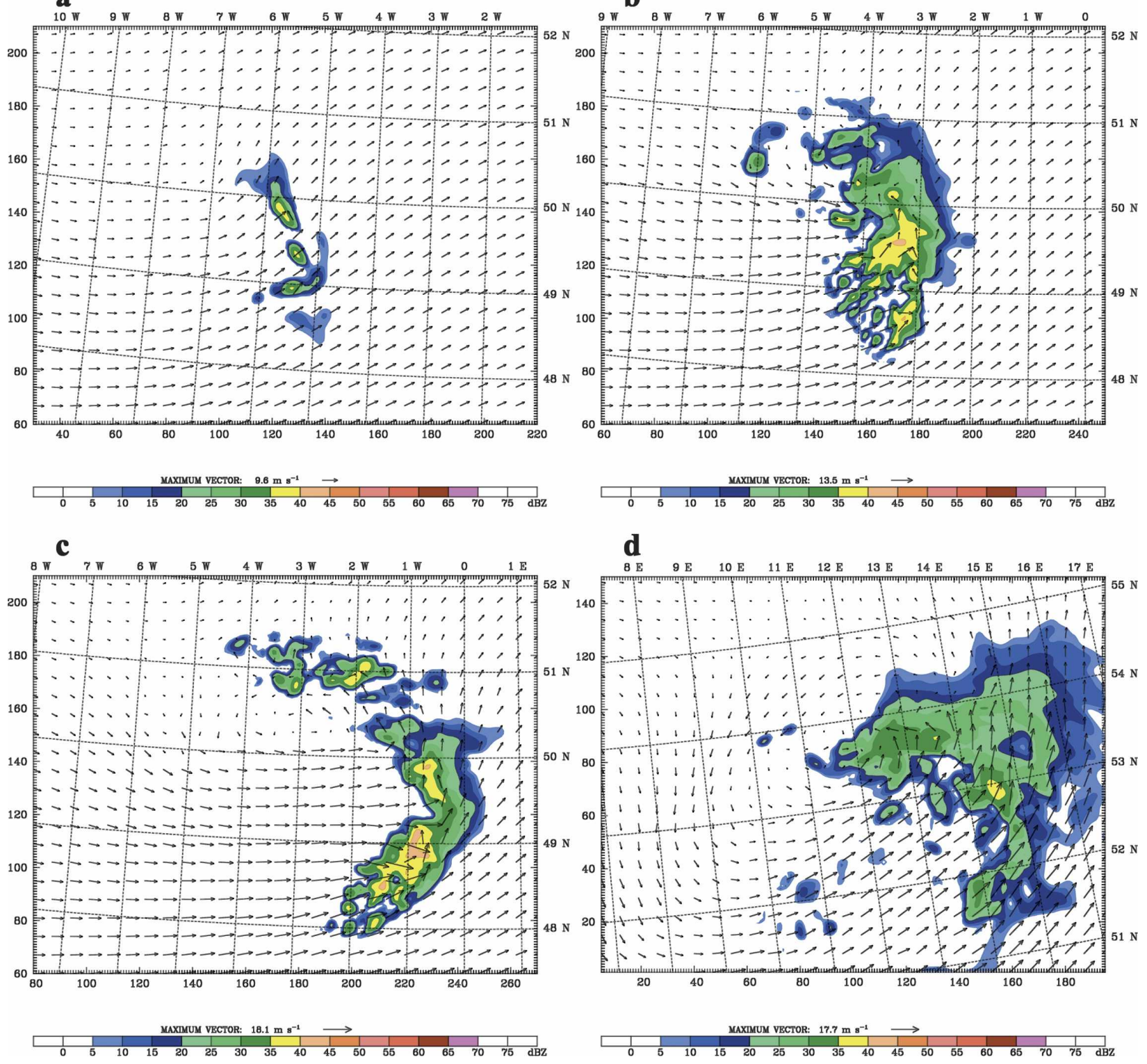

FIG. 3. Simulated radar reflectivity (dBZ; shading) and horizontal flow at $700 \mathrm{mb}$ (wind barbs) in the control simulation on the 3.3-km domain at simulation time: (a) 126, (b) 132, (c) 138, and (d) $174 \mathrm{~h}$.

refer to this system as an MCS and to the midlevel circulation that develops within it as an MCV. However, when we show that the circulation has the properties of a DRV, we will use the terms MCV and DRV interchangeably.

Approximately $2.5 \mathrm{~h}$ after the initialization of the finer scale domains, a single convective cell initiates and quickly develops into a quasi-linear, approximately north-south-oriented convective band over $200 \mathrm{~km}$ in length (Fig. 3a). Over the subsequent 12 h (Figs. 3b,c), the system acquires the characteristics of an MCS, with convective cells expanding initially, followed by a large increase in the horizontal extent of stratiform precipitation. Thereafter, convection becomes somewhat less prevalent (replaced with stratiform precipitation), and the structure of the entire system acquires more of a comma-head shape (Fig. 3d). The system translates to the east-northeast at a fairly constant speed of approximately $8 \mathrm{~m} \mathrm{~s}^{-1}$. Because the mesoscale system grows upscale, it becomes more difficult, by the end of the simulation, to distinguish the synoptic and mesoscale systems. Also, because of the near absence of deep convection late in the simulation, the system becomes less like an MCS, and the more general term DRV becomes 


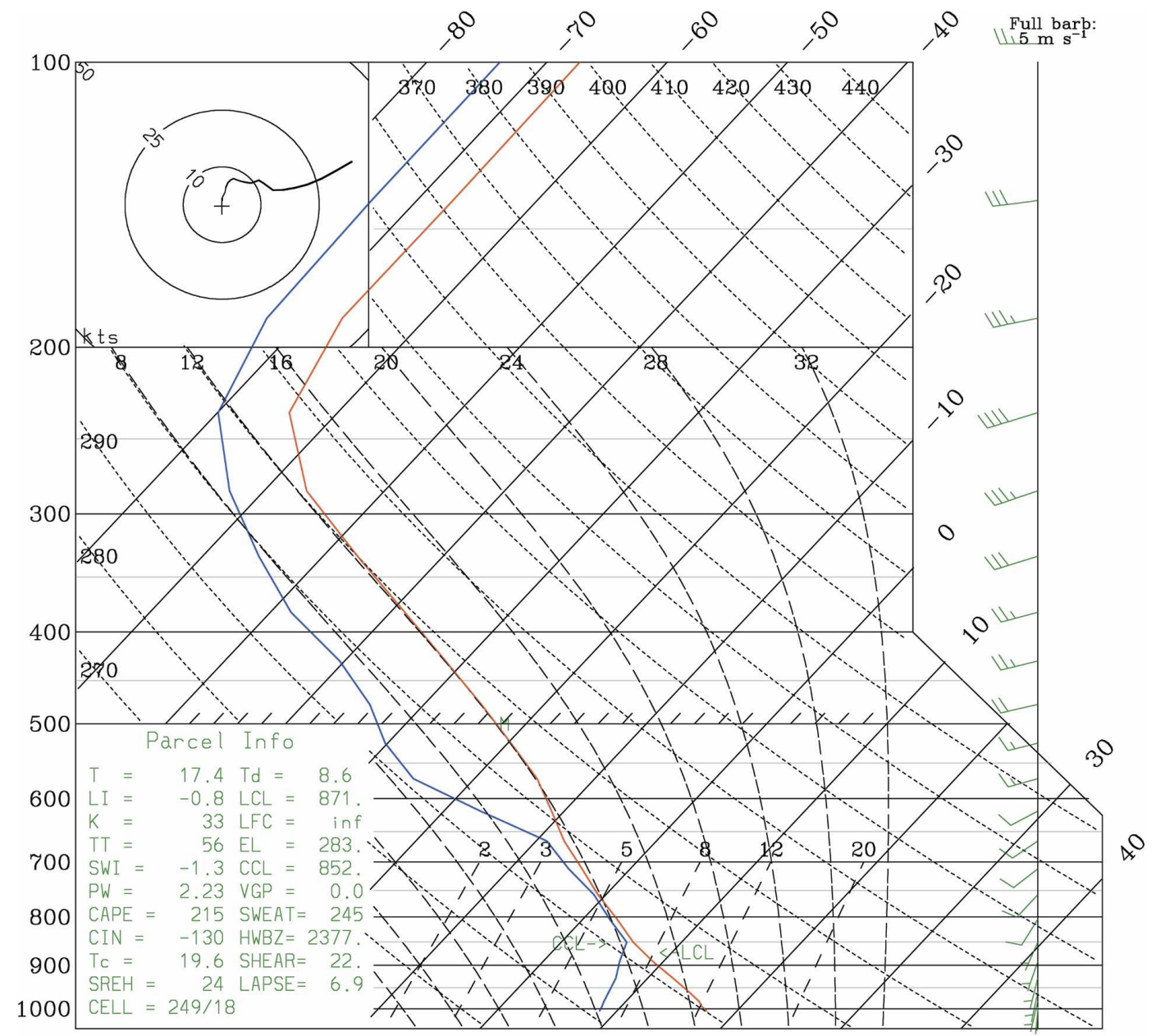

FIG. 4. Skew- $T$ diagram at time and location immediately before the onset of deep convection in the control simulation (simulation time of $124.8 \mathrm{~h}$; location at $49.5^{\circ} \mathrm{N}, 7^{\circ} \mathrm{W}$ ).

more applicable to the vortex (although it still has convective origins). With the purpose of exploring the DRV/MCV dynamics, we focus our analysis on the mesoscale system.

A skew- $T$ diagram representative of the local environment immediately before convective initiation is presented in Fig. 4. Through a combination of southerly moist advection and mesoscale lifting, an approximately $200-\mathrm{mb}$ layer ( 850 to $650 \mathrm{mb}$ ) above the wellmixed planetary boundary layer has undergone significant moistening (cf. with Fig. 1b). The atmosphere in this region is no longer moist neutral, with a surfacebased CAPE value of $215 \mathrm{~J} \mathrm{~kg}^{-1}$ in the presented sounding and up to $600 \mathrm{~J} \mathrm{~kg}^{-1}$ elsewhere. While the value of CAPE is quite meager in comparison with typical cases of MCV formation (see section 4), it appears the midlevel moistening process is necessary, in this model setup, for deep convection to ensue.
A similar process of environmental preconditioning was noted in MM05. In a relatively subsaturated environment, the moistening of the lower atmosphere was a critical step in the process of DRV formation. Both here and in MM05, the moistening occurs because of advection on the downshear side of the cyclonic, perturbation vortex. The low-level advection of high- $\theta_{e}$ air destabilizes the atmosphere sufficiently for further lifting to initiate convection.

The diurnal cycle in convection observed in earlier studies of MCVs (Fritsch et al. 1994; Trier and Davis 2002; Houze 2004) is absent here, consistent with the fact that the surface fluxes of latent and sensible heat have been neglected. With the lack of forcing on the diurnal time scale, deep convection is present over the entire diurnal cycle. The proposed mechanism for the nearly constant convective regeneration observed here will be discussed in section $3 \mathrm{c}$. 


\section{b. Formation and persistence of the $M C V$}

\section{1) Formation}

The first evidence of the formation of a midlevel circulation is observed approximately $6 \mathrm{~h}$ after the initiation of deep convection, with a cyclonic circulation emerging on the northern end of the convective band, as in Weisman and Davis (1998). Near the time of formation, the center of the incipient midlevel circulation resides in a region of stratiform precipitation. In a trailing stratiform precipitation region, the vertical structure of the diabatic heating is conducive to the formation of a middle-tropospheric positive PV anomaly. An examination of the $\mathrm{PV}$ equation shows that where there is a positive gradient of diabatic heating along the direction of the vorticity vector, positive PV will be produced. The diabatic heating gradient is large and positive in the midtroposphere, above the lowertropospheric evaporative cooling and below the uppertropospheric stratiform heating (Hertenstein and Schubert 1991). However, a large positive gradient is also found in the lower tropospheric portion of typical convective diabatic heating profiles (Houze 1997, 2004), motivating the question of whether convective or stratiform processes contribute more to the vertical diabatic heating gradients. This question will be addressed in a later study.

Although a very weak DRV signature is present before convection initiates, the convection plays the leading role in the overall development of the midlevel PV maximum. At $t=120 \mathrm{~h}$ (Figs. 5a,c), the vortex is rather weak and somewhat disorganized, with PV maxima both near the surface and in the midtroposphere. By $t=$ 134.4 h (Figs. 5b,d), after convection has been present for several hours, the vertical structure (Fig. 5b) is more characteristic of a DRV. The vortex has intensified and acquired much better vertical coherence, with a midlevel PV maximum of about 1.6 potential vorticity units (PVU; $1 \mathrm{PVU}=10^{-6} \mathrm{~m}^{2} \mathrm{~s}^{-1} \mathrm{~K} \mathrm{~kg}^{-1}$ ) at approximately $700 \mathrm{mb}$ and a localized PV minimum in the upper troposphere, slightly downshear of the PV maximum. Below (above) the level of PV maximum, a cold (warm) temperature anomaly is predicted (Fig. 5b). The vertical potential temperature gradient has increased in the lower and middle troposphere, but near the tropopause, the gradient has decreased. Such a structure is characteristic of a DRV (RJ90; JR95; MM04; MM05) and qualitatively consistent with previous observational and modeling results of MCVs (RJ90; Fritsch et al. 1994; JR95). Given the similarity of the structures, MCVs can be thought of as a subcategory of DRVs originating from MCSs. The predicted downshear tilt of the vortex is expected given the deep tropospheric shear of the environment. It will be later suggested (section 3c) that this tilt is important for the vortex intensification.

At $700 \mathrm{mb}$, a cyclonic circulation and a small magnitude warm anomaly are associated with the PV maximum (Fig. 5d). The approximate horizontal extent of the MCV at this time is $300 \mathrm{~km}$, well within the accepted range of MCV scales. The presence of closed contours of PV on an isentropic surface through this level (not shown) illustrate the disturbance is a coherent structure (Davis et al. 2002).

When looking at the component of PV due to relative vorticity (Fig. 6), it is evident that the vortex intensity, measured by the relative vorticity, changes most remarkably between 120 and $132 \mathrm{~h}$ into the simulation (Figs. 6a,b), when the convective development occurs. As the stratiform precipitation area expands (see Figs. $3 \mathrm{c}, \mathrm{d}$ ), so does the width of the vortex itself (Figs. 6c,d). This finding is consistent with previous DRV studies that illustrate that, in the presence of near-continuous convection, the disturbance grows in both size and amplitude with time (RJ90; JR95; MM04; MM05). In their observational study of a multiday MCV event, Fritsch et al. (1994) note that the size and intensity of the MCV tended to grow during convective events. With the absence of a diurnal cycle in convection, the simulation presented here can be thought of as an uninterrupted diabatic-heating event and, therefore, it is expected that the size and intensity of the disturbance would grow continuously with time. The convection is gradually replaced with an expanding area of stratiform precipitation as the cold pool expands, the system grows upscale, and much of the CAPE is removed. However, the diabatic heating associated with the stratiform precipitation continues to reinforce the vortex.

\section{2) Mechanism FOR PeRsistence}

Given the depth and strength of the shear in the basic-state environment, it might seem somewhat surprising that the DRV is not sheared apart with time. Rather, its tilt does not change significantly over the simulation. Previous work on DRV and MCV evolution has illustrated that the regeneration of PV associated with primarily convective processes offsets the deleterious effect of vertical shear and allows the PV couplet to remain intact (RJ90; JR95; Trier et al. 2000a; MM04; MM05). In the present numerical experiment, convection develops after $t=126 \mathrm{~h}$ and is associated with the intensification of the vortex. At later stages of the simulation, the convection wanes, due to decreasing CAPE, but it is replaced by an increasing area of strati- 
$\mathbf{a}$

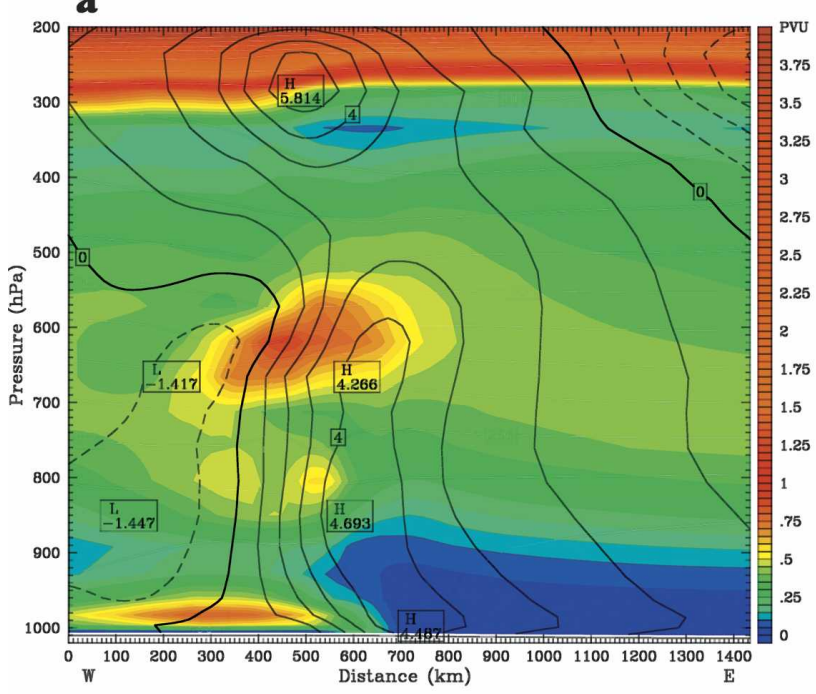

C

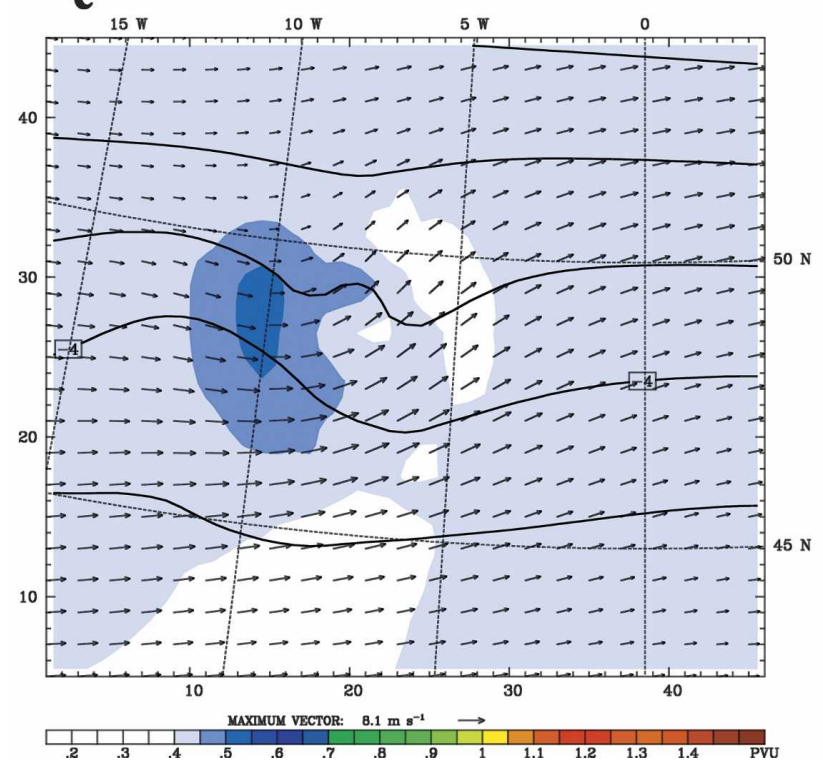

b

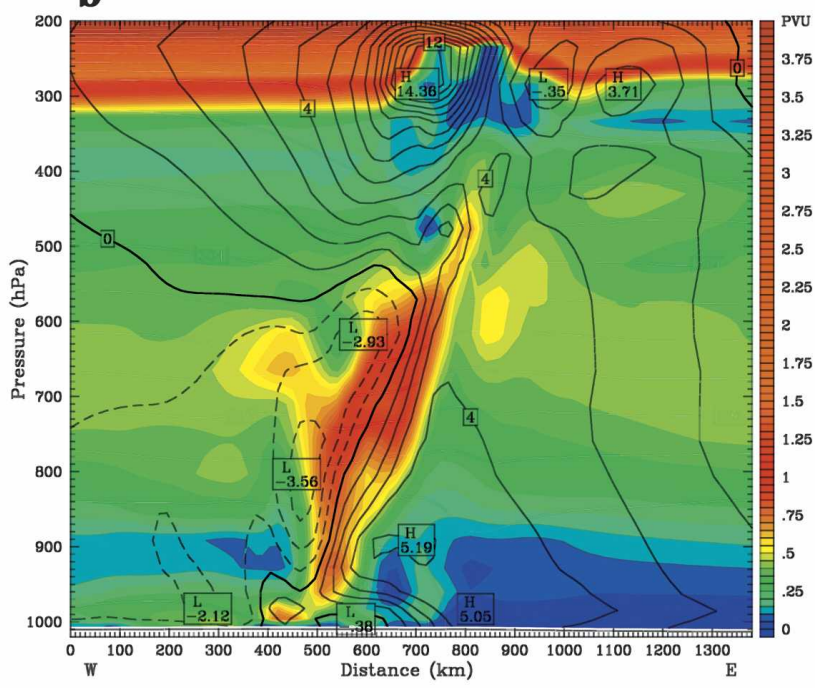

d

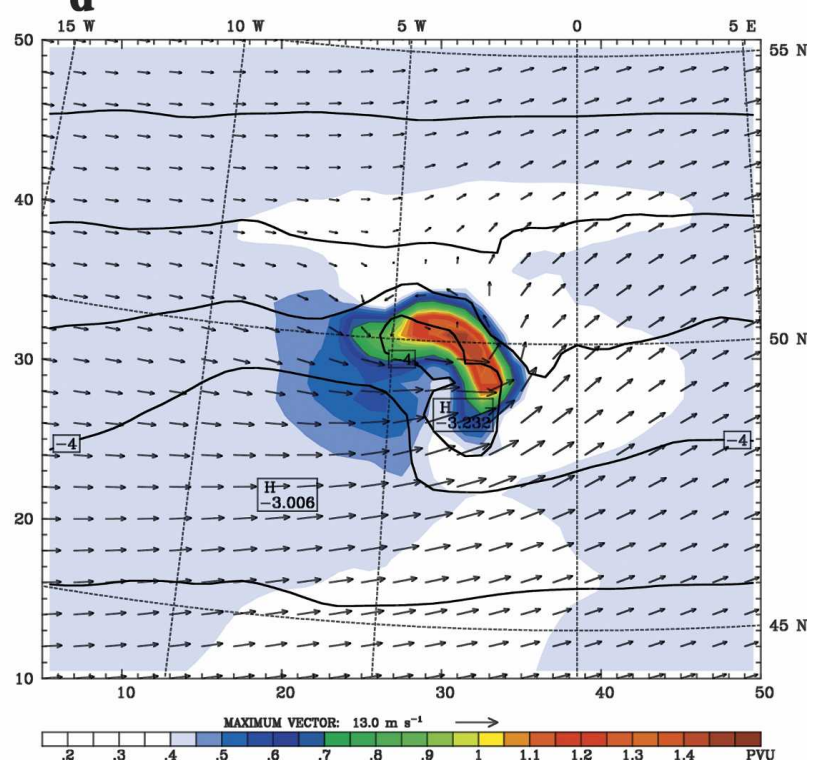

FIG. 5. Three-dimensional structure of the incipient vortex in the control simulation on the 30-km grid before and after deep convection: longitude-pressure cross section of the potential vorticity (PVU, or $10^{-6} \mathrm{~m}^{2} \mathrm{~s}^{-1} \mathrm{~K} \mathrm{~kg}^{-1}$; shading), potential temperature (white contour lines; interval is $1 \mathrm{~K}$ ), and meridional velocity (black lines; contour interval is $1 \mathrm{~m} \mathrm{~s}^{-1}$; dashed lines for negative contours) at (a) $t=120 \mathrm{~h}$ along a cross section at $48^{\circ} \mathrm{N}$ from $15^{\circ} \mathrm{W}$ to $5^{\circ} \mathrm{E}$; and (b) $t=134.4 \mathrm{~h}$ along a cross section at $50^{\circ} \mathrm{N}$ from $13^{\circ} \mathrm{W}$ to $7^{\circ} \mathrm{E}$; and potential vorticity (PVU; shading), temperature (K; black contour lines), and horizontal flow (wind barbs) at $700 \mathrm{mb}$ at (c) 120 ; and (d) $134.4 \mathrm{~h}$. In (a) and (b), potential temperature and meridional velocity are averages over a 60-km distance perpendicular to, and centered on, the cross section.

form precipitation, and the diabatic heating continues as the vortex retains its strength. This initial, qualitative evidence shows that the DRV mechanism is active in sustaining the vortex, but it is not the only possible mechanism. The vortex might alternatively be persistent because of its internal dry dynamics.

Because DRVs/MCVs are coherent structures, they tend to resist small perturbations, and their structure remains intact (Montgomery and Kallenbach 1997; Davis et al. 2002). As a result, MCVs have been observed to maintain their coherence in the absence of moist convection for 6-12 h or more in regions of relatively weak shear (Davis et al. 2002; Reasor et al. 2004). Schecter et al. (2002) and Reasor et al. (2004) present a linear theory that may explain the vortex resiliency through dry vortex Rossby wave dynamics. Within the 
$\mathbf{a}$

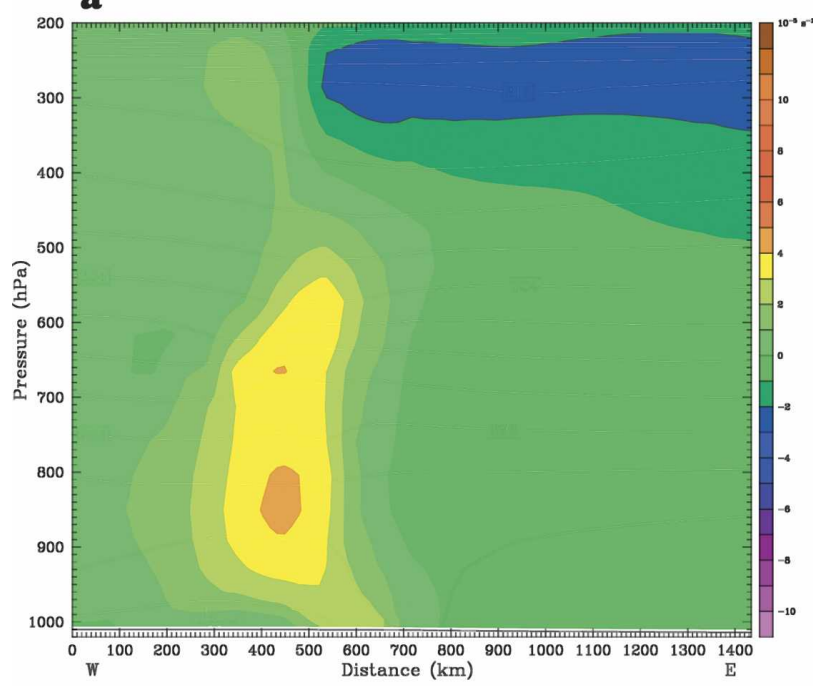

c

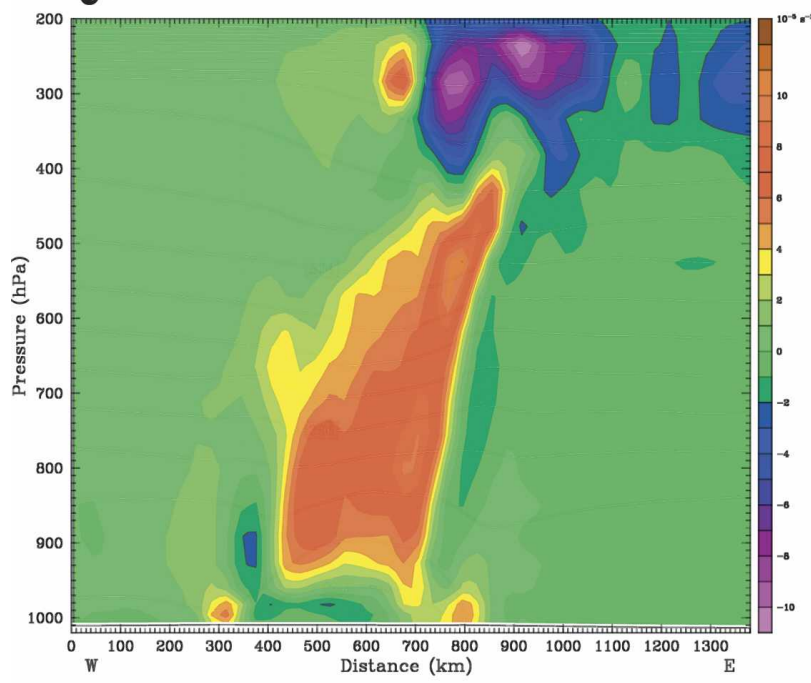

b

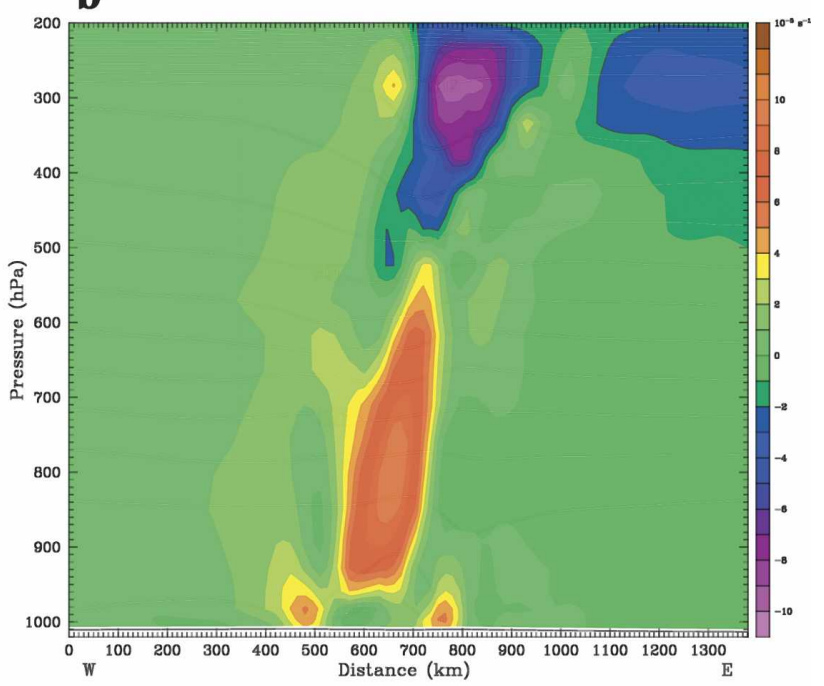

d

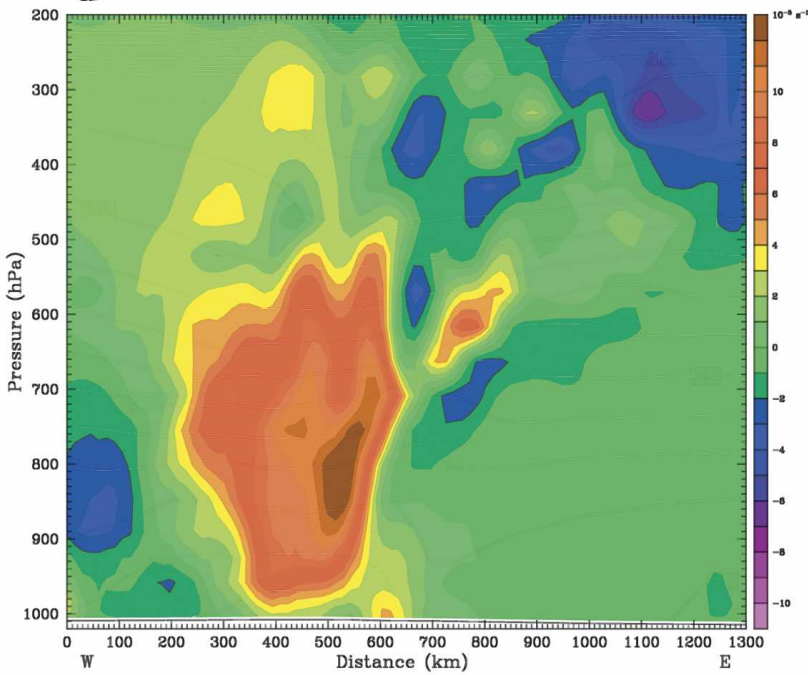

FIG. 6. Cross sections of relative vertical vorticity $\left(\mathrm{s}^{-1}\right.$; shading) and potential temperature (white lines; contour interval is $\left.2 \mathrm{~K}\right)$ in the control simulation on the $30-\mathrm{km}$ grid at simulation times (a) $t=120 \mathrm{~h}$ along $48^{\circ} \mathrm{N}$ from $15^{\circ} \mathrm{W}$ to $7^{\circ} \mathrm{E}$; (b) $t=132 \mathrm{~h}$ along $50^{\circ} \mathrm{N}$ from $14^{\circ} \mathrm{W}$ to $6^{\circ} \mathrm{E}$; (c) $t=137.6 \mathrm{~h}$ along $50^{\circ} \mathrm{N}$ from $12^{\circ} \mathrm{W}$ to $8^{\circ} \mathrm{E}$; and (d) $t=173.6 \mathrm{~h}$ along $53^{\circ} \mathrm{N}$ from $5^{\circ}$ to $25^{\circ} \mathrm{E}$, respectively. Values plotted are averages over a $180-\mathrm{km}$ distance perpendicular to, and centered on, the cross section.

context of vortex resiliency theory, the tilting of the vortex, induced by shear, is described in terms of a wavenumber-1 vortex Rossby wave (VRW). As a response to this imposed perturbation, the resilient vortex precesses because of the propagation of the VRW around the vortex center. Eventually, the vortex realigns (becomes upright again) or reaches a quasisteady-state tilt to the left of the shear vector.

However, the VRW process is too slow for the realignment process to be effective in this case. At $t=134$ $\mathrm{h}$ in the simulation, the maximum tangential wind speed is $5 \mathrm{~m} \mathrm{~s}^{-1}$ at a radius of approximately $100 \mathrm{~km}$. It would require only $4 \mathrm{~h}$ for the basic-state shear (1.5 $\mathrm{m} \mathrm{s}^{-1} \mathrm{~km}^{-1}$ ) to displace the upper-tropospheric segment of the vortex (at a height of $10 \mathrm{~km}$ ) a distance of one vortex diameter from the surface vortex position, whereas it would require $35 \mathrm{~h}$ for the vortex to make a full revolution at its radius of maximum winds. Vortex resiliency must be ruled out as a mechanism of persistence in this case as well as in most other cases (Davis et al. 2002). However, the MCV observed in the BAMEX intensive observation period (IOP) 8 (see section 4) had weaker shear and stronger rotation, such that their time scales were approximately equal, so pre- 
a

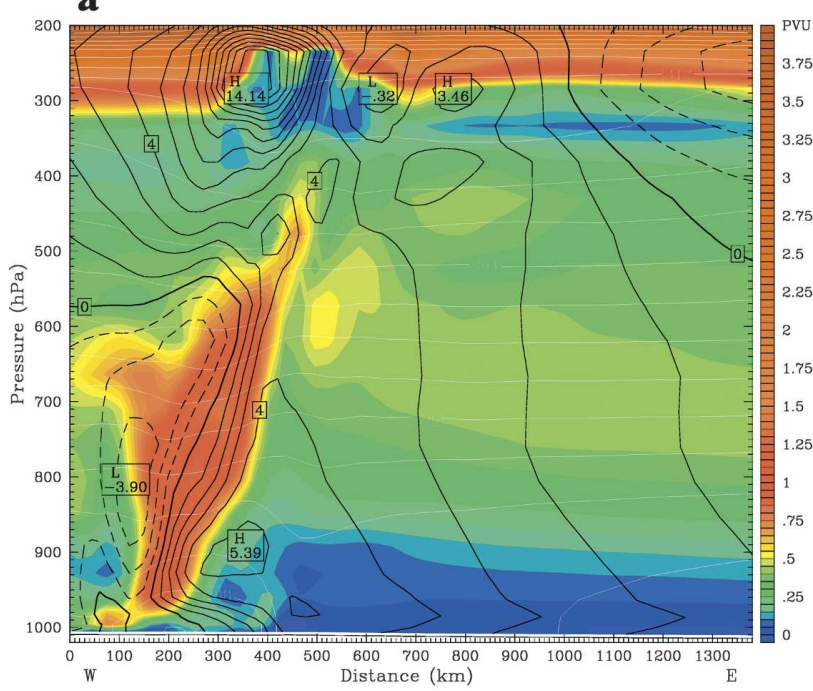

c

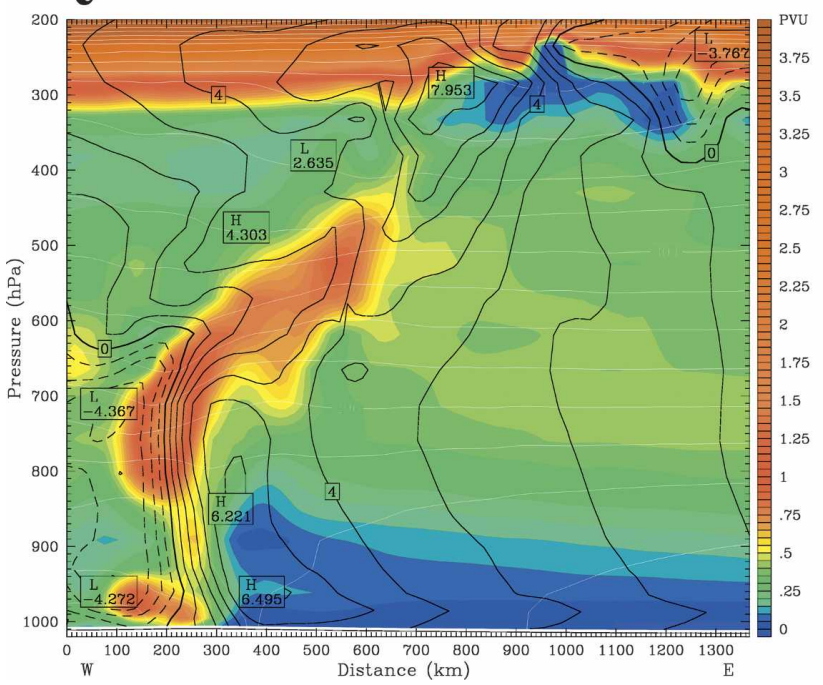

b

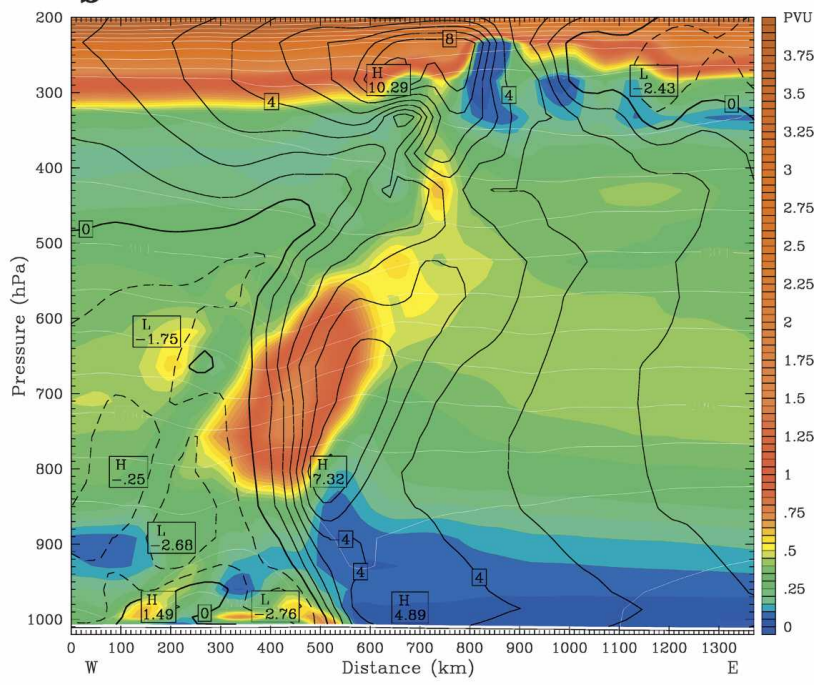

d

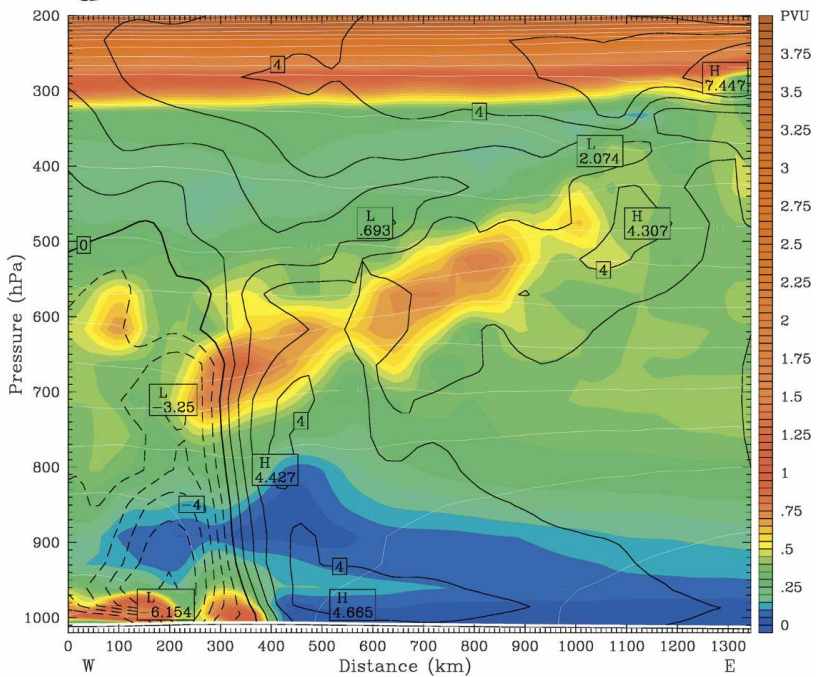

FIG. 7. Ertel's potential vorticity (PVU; shading), potential temperature (white lines; contour interval is $2 \mathrm{~K}$ ), and meridional flow (black lines; contour interval is $1 \mathrm{~m} \mathrm{~s}^{-1}$; dashed lines for negative contours) for the simulation with latent heating removed (dry run) on the $30-\mathrm{km}$ grid at simulation times and cross sections: (a) $t=134.4 \mathrm{~h}$ (latent heating is turned off) along $50^{\circ} \mathrm{N}$ from $8^{\circ} \mathrm{W}$ to $12^{\circ} \mathrm{E}$; (b) $t=140 \mathrm{~h}$ from $50.3^{\circ} \mathrm{N}, 9^{\circ} \mathrm{W}$ to $50.5^{\circ} \mathrm{N}, 11^{\circ} \mathrm{E}$; (c) $t=145.6 \mathrm{~h}$ along $50.5^{\circ} \mathrm{N}$ from $5^{\circ} \mathrm{W}$ to $15^{\circ} \mathrm{E}$; and (d) $t=156 \mathrm{~h}$ from $51^{\circ} \mathrm{N}, 5^{\circ} \mathrm{W}$ to $52^{\circ} \mathrm{N}, 15^{\circ} \mathrm{E}$, respectively. The potential temperature and meridional velocity values are averages over a $60-\mathrm{km}$ distance perpendicular to, and centered on, the cross section.

cession could have been a contributor to the persistence of the vortex in that case.

To further demonstrate this conclusion, as well as the primary importance of convection, we conducted a simulation in which the latent heating was turned off at $t=134.4 \mathrm{~h}$. At this time (Fig. 7a), the PV structure is well developed, with a midlevel positive PV anomaly and a negative anomaly at $300 \mathrm{mb}$. In less than $6 \mathrm{~h}$ (Fig. $7 b$ ), the vortex has become more tilted, with the upperlevel PV minimum becoming displaced farther downshear from the midlevel maximum. A few hours later
(Fig. 7c), the vortex appears to regain some of its original low-level structure, but it is also extruding negative PV anomalies downshear. In less than a day after removal of the latent heating (see Fig. 7d), the vertical coherence of the DRV has been nearly eliminated. A highly sheared positive PV anomaly remains between 750 and $400 \mathrm{mb}$, and the upper-level PV minimum has been advected out of the field of view of Fig. 7d. What remains is a somewhat more intense (in terms of relative vorticity) low-level vortex with little remaining PV anomaly in the interior (note the small PV around 900 
$\mathrm{mb}$ ). The apparent vortex recovery maybe partly a function of the cross section locations chosen for presentation in Fig. 7, but different choices of these locations all indicated some vortex recovery.

The intensification of the low-level vortex is of some interest and, at first glance, seems to occur in a similar manner as described in Johnson et al. (1989), in which the mesolow formed as the MCS and associated precipitation dissipated. In their observations, the mesolow formed as a result of hydrostatic pressure changes due to mesoscale downdrafts and subsidence warming as the cold pool spread and dissipated. In our simulation, some weak subsidence was likewise noted over the cold pool. However, the low- to midlevel vorticity maximum also moved downshear from the cold pool, and for a time, the juxtaposition of the vortex with the temperature gradient at the downshear end of the cold pool allowed some low-level baroclinic intensification to occur. The surface pressure decreased by approximately 2 mb between $t=145.6 \mathrm{~h}$ (Fig. 7c) and $t=168 \mathrm{~h}$ (not shown). Beyond $t=168 \mathrm{~h}$, however, some synoptic scale baroclinic development may have also contributed to this deepening. Without the deep, moist convection (Fig. 7), the shear has eliminated the signature DRV PV structure.

\section{c. Balanced flow diagnosis}

The location of convective regeneration has important repercussions for the longevity of the disturbance. For the DRV to survive in a vertically sheared environment, there must be a feedback between convective processes and DRV intensity. It is clearly beneficial if the midlevel disturbance is in part or in whole placed in the region of persistent, deep lifting where stretching of vorticity can occur and where diabatic processes are occurring that can increase the vertical gradient of potential temperature.

To examine if the DRV growth mechanism is at work in the control simulation, the time sequence of the 700$\mathrm{mb}$ vertical velocity, horizontal wind, and temperature are presented in Fig. 8. At all times, the maximum vertical velocity at this level is located in or near a region of enhanced baroclinicity, where there is strong southwesterly flow associated with the cyclonic circulation of the MCV. The constant collocation of enhanced baroclinicity, cross-isentropic flow, and a mesoscale updraft provides strong anecdotal evidence that balanced lifting, through the interaction of the DRV with the sheared environment, is playing a primary role in the destabilization.

Many previous studies have noted the importance of low-level warm, moist advection in the regeneration of convection (RJ90; Fritsch et al. 1994; JR95; Davis and
Trier 2002; Trier and Davis 2002), often in association with the nocturnal low-level jet. The influx of high- $\theta_{e}$ air is responsible for destabilizing the atmosphere. The 850 -mb water vapor mixing ratio, horizontal wind, and temperature fields are presented in Fig. 9. Associated with the lower-level cyclonic circulation, strong southwesterly flow is advecting warm, moist air into the system, into the region where deep convection is occurring.

In the present study, the lack of a true diurnal cycle and the lack of topography preclude the presence of a nocturnal low-level jet. It is therefore clear that the influx of warm moist air is primarily due to the balanced motion associated with the MCV. To provide better quantification, the vertical velocity was calculated using the same nonlinear balance model as in Trier and Davis (2002). The choice of the nonlinear balance constraint for this case can be justified by its successful use in previous studies examining meteorological phenomena with such varying time and length scales as synoptic-scale cyclones (Davis et al. 1996) and MCVs (JR95; Davis and Weisman 1994; Olsson and Cotton 1997a,b). Although the degree of balance may differ somewhat among MCVs, these studies found such balanced dynamics to play the leading role in MCV maintenance and longevity.

The balanced vertical velocity calculations were performed at $t=135.2 \mathrm{~h}$ and $t=171.2 \mathrm{~h}$ for the control simulation. In both cases, the location of the balanced vertical motion corresponds well to the location of the precipitation (Fig. 10). The overall finding agrees with that of Davis and Trier (2002) who noted that that the MCV itself was instrumental in transporting warm moist air into the system, thereby invigorating and prolonging the convection.

The picture that emerges is that of a coherent vortex, with maximum amplitude in the lower to middle troposphere, which interacts with the sheared environment to continuously produce convection in a region that is conducive to the further intensification of the vortex itself. Given the consistency with theory, we believe the DRV growth mechanism provides an excellent model for a better understanding of convective regeneration, $\mathrm{MCV}$ intensification and the long-lived nature of the MCV.

One particularly noteworthy feature of Fig. $9 \mathrm{c}$ is the evidence of two scales within the simulated system, as has been discussed in section $3 b(1)$. The MCV is clearly seen as a closed circulation at $53^{\circ} \mathrm{N}, 12^{\circ} \mathrm{E}$, and the synoptic scale, moist baroclinic system is a more wavelike feature that spans the entire horizontal area displayed in the plot. The existence of the larger scale system, within which the MCV resides, adds some confusion 

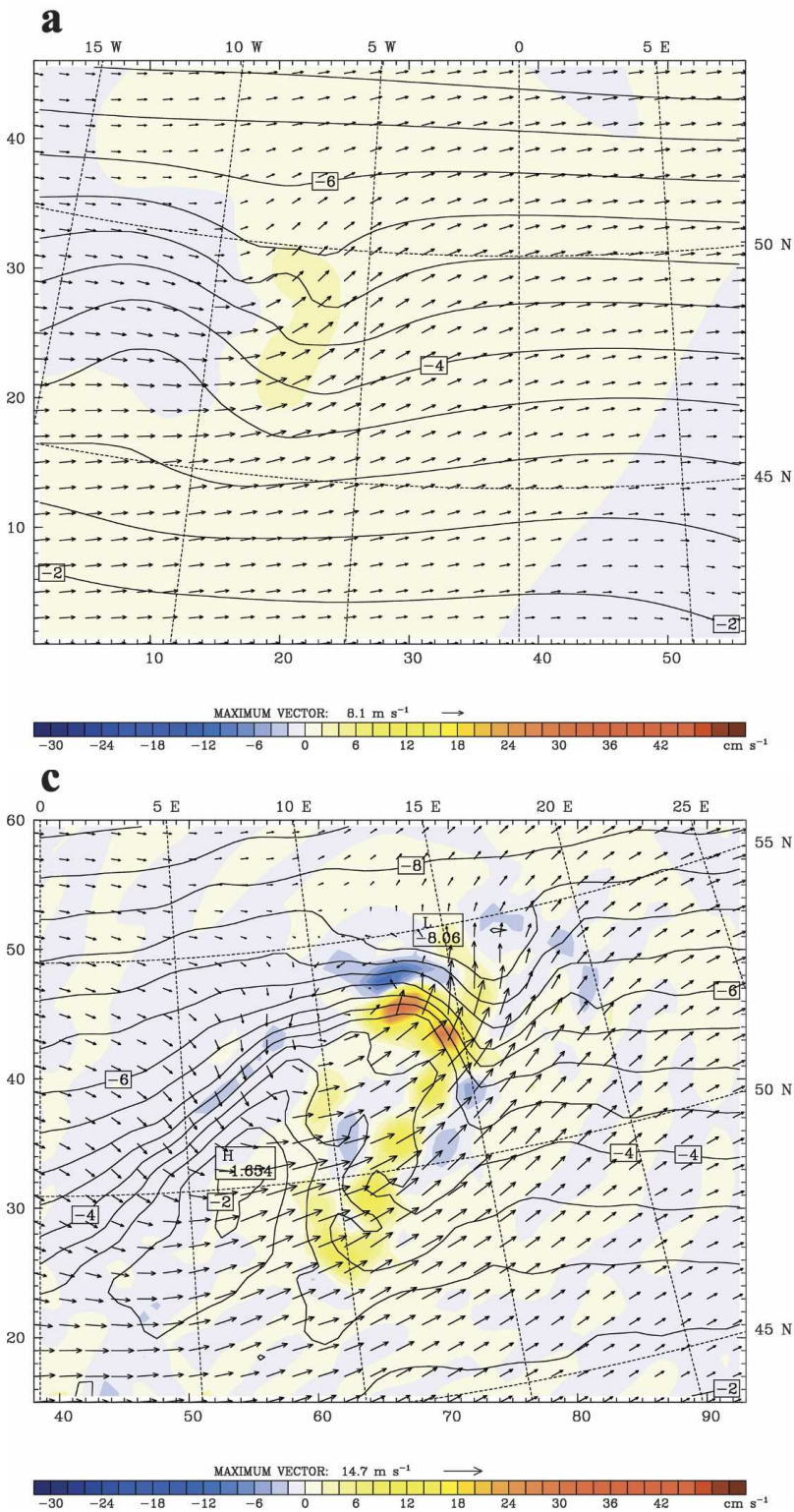

over whether the MCV would exist without the contributions of the larger baroclinic system to the warm, moist inflow into the MCV. Clearly, the balanced vertical velocity calculations (Fig. 10) indicate that the majority of the balanced forcing is occurring on the scale of the MCV, yet Figs. 8 and 9 show the temperature and moisture advection patterns extend downshear of the MCV.

The balanced vertical motion (and accompanying moistening of the midtroposphere) and low-level moist advection by vortex tangential flow (moistening the lower troposphere and producing CAPE) appear to play similarly large roles in forcing deep convection. Although a more detailed investigation, such as a tra- b

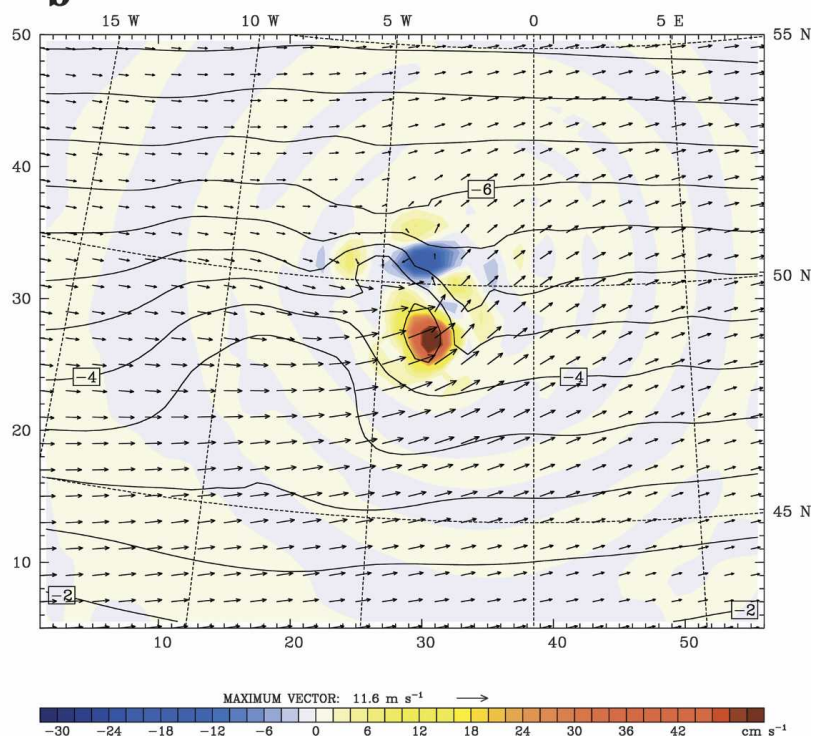

FIG. 8. Vertical velocity $\left(\mathrm{cm} \mathrm{s}^{-1}\right.$; shading), temperature (black contour lines; interval is $0.5 \mathrm{~K}$ ), and flow field (wind barbs) at 700 $\mathrm{mb}$ on the $30-\mathrm{km}$ grid of the control simulation at simulation time (a) 120, (b) 132, and (c) $173.6 \mathrm{~h}$, respectively. jectory analysis, might provide a more complete answer, Figs. 4, 9b, and 10a provide enough information, within the scope of the present study, to make a rough estimate of the relative magnitudes of both these processes. Looking at Fig. 10a, one can see that the balanced lifting is approximately $1 \mathrm{~cm} \mathrm{~s}^{-1}$. Given that the water vapor mixing ratio changes from 3.5 to $6.5 \mathrm{~g} \mathrm{~kg}^{-1}$ between 850 and $700 \mathrm{mb}$ (a depth of approximately $1500 \mathrm{~m}$; see Fig. 4), we estimate the rate of change of water vapor mixing ratio due to balanced lifting to be $2 \times 10^{-5} \mathrm{~g} \mathrm{~kg}^{-1} \mathrm{~s}^{-1}$. Looking at Fig. 9, we can estimate the moistening due to horizontal (on a constant pressure surface) advection to be approximately $3 \times 10^{-5} \mathrm{~g}$ $\mathrm{kg}^{-1} \mathrm{~s}^{-1}$ (using an estimated balanced tangential veloc- 

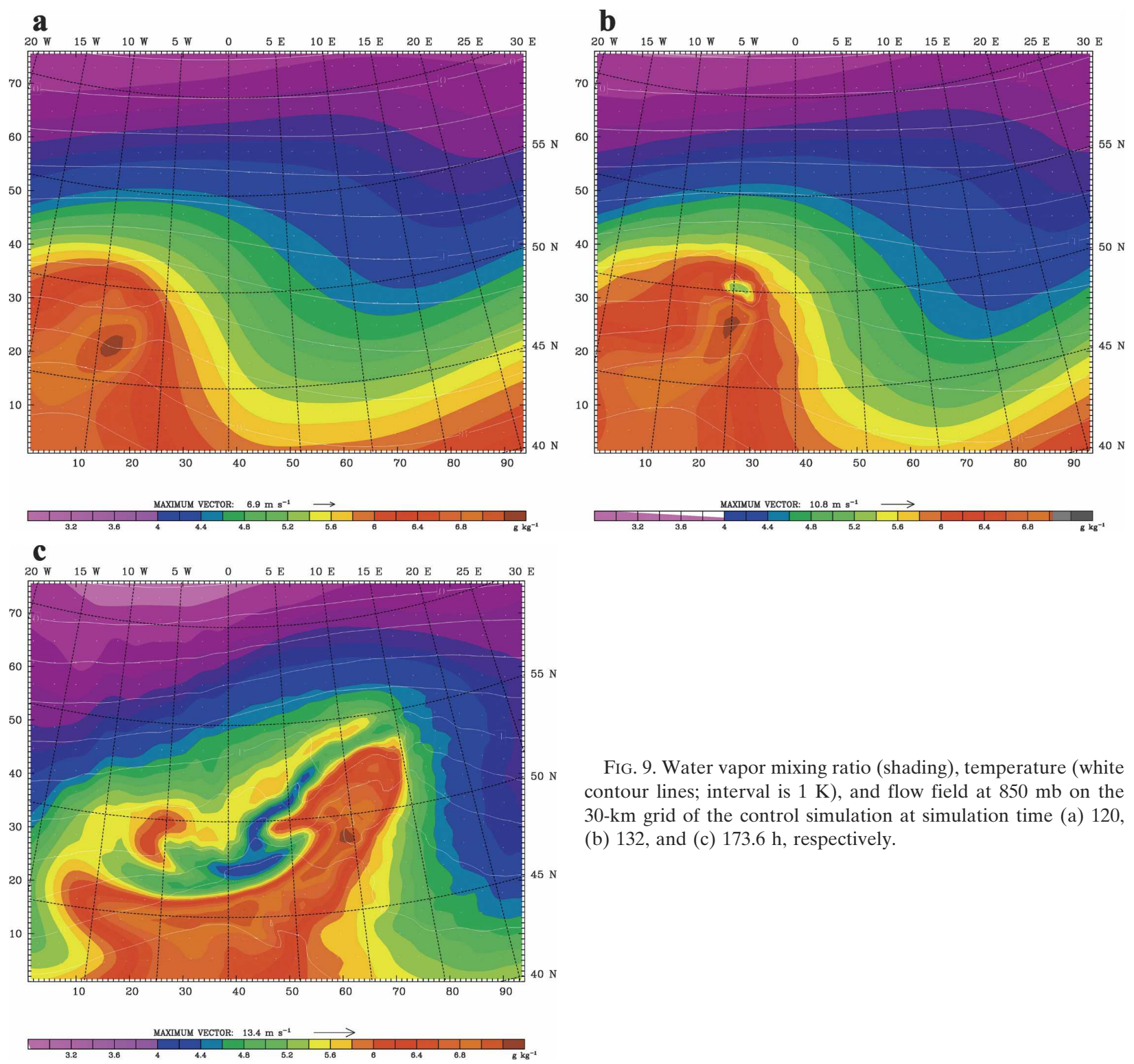

FIG. 9. Water vapor mixing ratio (shading), temperature (white contour lines; interval is $1 \mathrm{~K}$ ), and flow field at $850 \mathrm{mb}$ on the $30-\mathrm{km}$ grid of the control simulation at simulation time (a) 120 , (b) 132, and (c) $173.6 \mathrm{~h}$, respectively.

ity of $5 \mathrm{~m} \mathrm{~s}^{-1}$ ), which is about the same order of magnitude as the midlevel moistening due to balanced lift.

A more formal-scale analysis involves the estimate of the relative contributions of horizontal and vertical advection of moist static energy $s_{e}$ :

$$
s_{e}=c_{p} T+g z+L_{v} q
$$

where $q$ is the water vapor mixing ratio, $L_{v}=2.5 \times 10^{6}$ $\mathrm{J} \mathrm{kg}^{-1}$ is the latent heat of vaporization, and $z$ is the height above some reference level. To calculate transport of moist static energy, we can use the same values of moisture and vertical and tangential velocity from the previous analysis and estimate the horizontal and vertical temperature gradients from Figs. 4 and 9b, respectively. Estimating the vertical temperature gradient as $-11 \mathrm{~K}(1500 \mathrm{~m})^{-1}$ (between 850 and $700 \mathrm{mb}$ ) and the horizontal gradient as $-1 \mathrm{~K}(180000 \mathrm{~m})^{-1}$, we find the vertical advection of moist static energy to be 0.03 $\mathrm{m}^{2} \mathrm{~s}^{-3}$ and the horizontal advection to be $0.09 \mathrm{~m}^{2} \mathrm{~s}^{-3}$ for a ratio

$$
\frac{v\left(\partial s_{e} / \partial y\right)}{w\left(\partial s_{e} / \partial z\right)}=3
$$

In the calculation of the vertical advection, we find some cancellation between the first two terms, $c_{p} T$ and $g z$, resulting in a net negative contribution from these two terms, but the advection of water vapor more than 
a
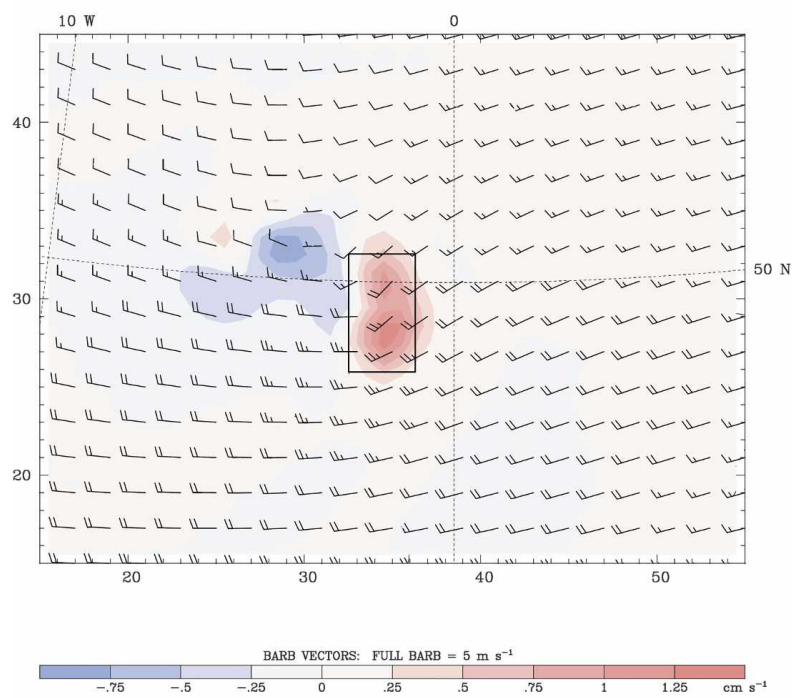

\section{c}
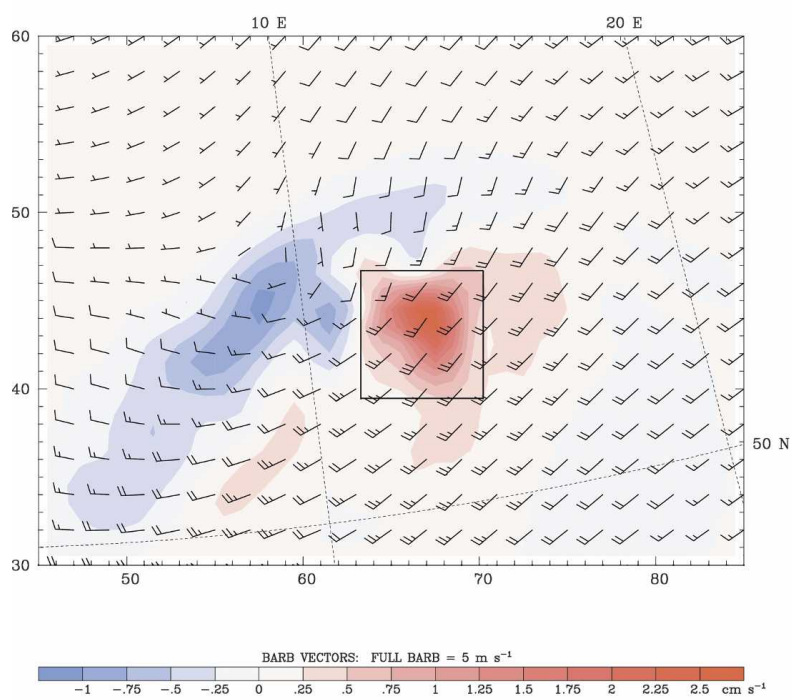
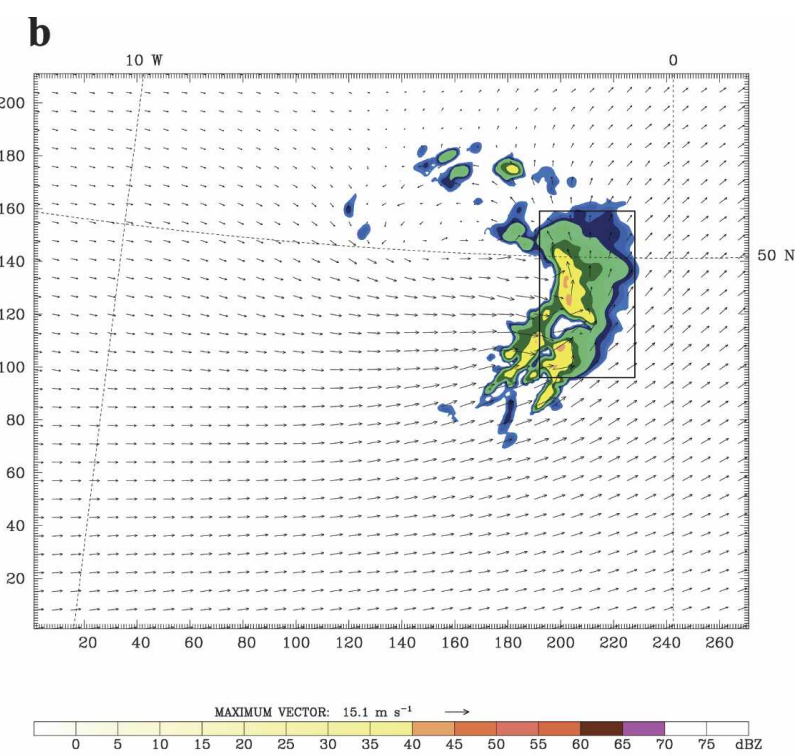

d

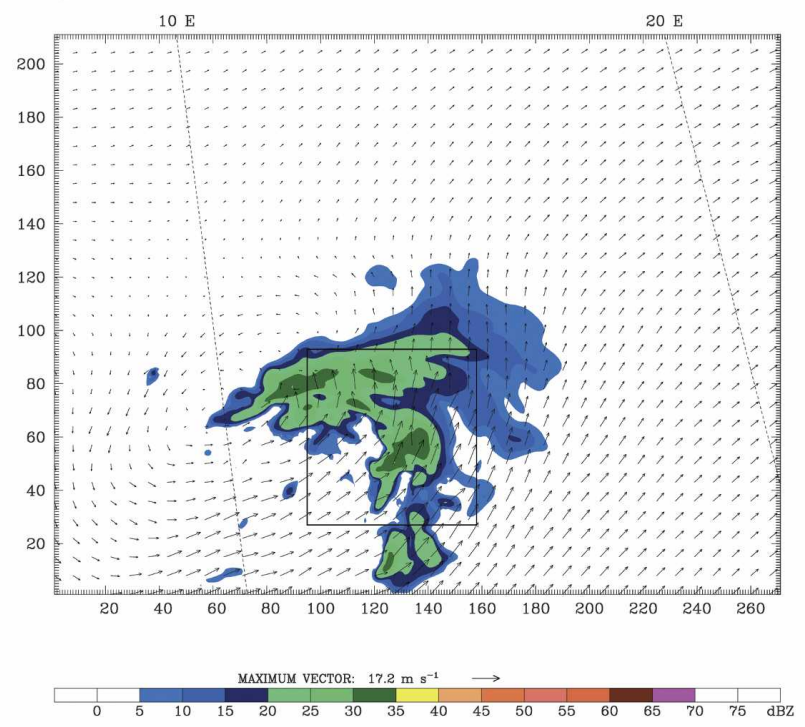

FIG. 10. Comparison between locations of balanced vertical motion and precipitation in the control simulation. At $t=135.2 \mathrm{~h}$ : (a) balanced vertical motion $\left(\mathrm{cm} \mathrm{s}^{-1}\right)$ and (b) 700-mb derived reflectivity $(\mathrm{dBZ})$; at $t=171.2 \mathrm{~h}$ : (c) balanced vertical motion ( $\left.\mathrm{cm} \mathrm{s}^{-1}\right)$ and (d) 700-mb derived reflectivity (dBZ). The boxes in (a) and (c) indicate the same areas as the boxes in (c) and (d), respectively.

compensates, and the vertical advection of moist static energy is positive overall. In the horizontal advection, both terms $c_{p} T$ and $L_{v} q$ contribute positively. It is also noted that if the actual (balanced plus unbalanced) vertical velocity (Fig. 8) is used, the contribution of vertical advection increases approximately an order of magnitude.

\section{d. Scale interaction and energy conversion}

Motivated by the existence of the larger baroclinic system, we conducted a sensitivity simulation using a more isolated initial low-level radial potential temperature profile (see section 2d). Because the results of the simulation lend themselves to comparison with the control simulation using energy conversion calculations, we present them in this section.

\section{1) Control simulation}

Figure 11a shows the baroclinic and diabatic energy conversion terms, as well as the trend in surface pressure, for the control simulation. The intensification of the system in terms of surface pressure occurs in two 

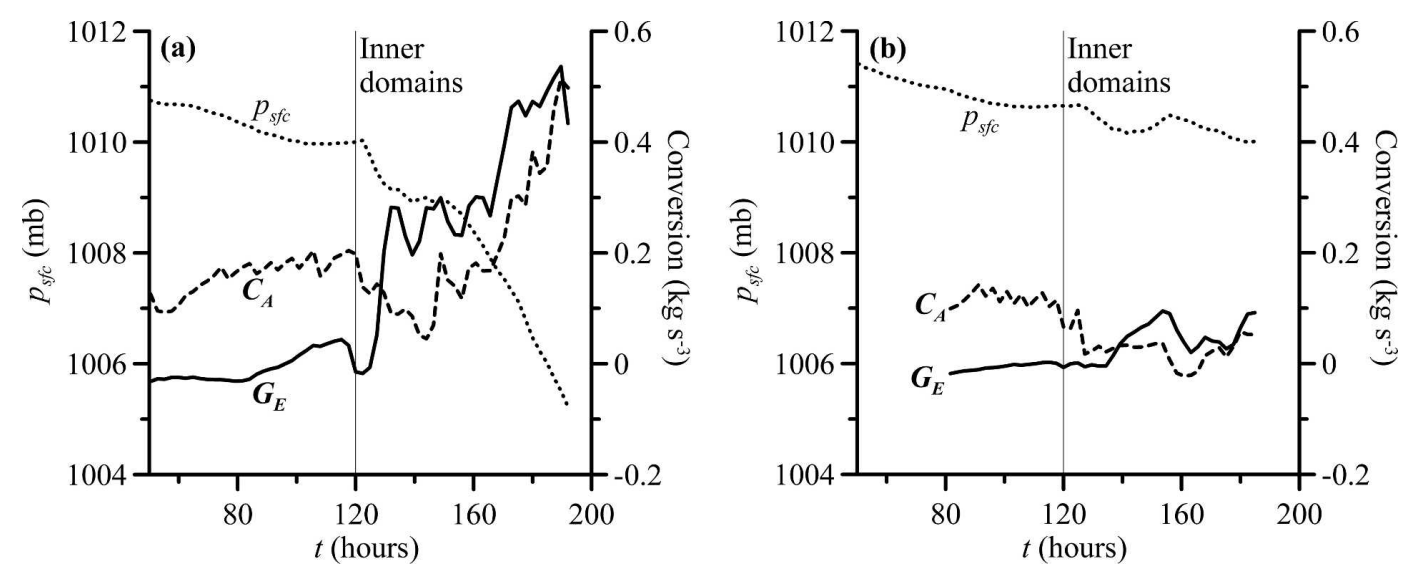

FIG. 11. Time series of the minimum surface pressure ( $\mathrm{mb}$; dotted line), conversion of basic-state APE to eddy $\operatorname{APE}\left(C_{A} ; \mathrm{kg} \mathrm{s}^{-3}\right.$; solid line), and conversion of diabatic heat energy to eddy APE $\left(G_{E} ; \mathrm{kg} \mathrm{s}^{-3}\right.$; dashed line), computed on the $90-\mathrm{km}$ grid for a $2700 \times 1800 \mathrm{~km}^{2}$ box centered on the surface pressure minimum for (a) the control simulation and (b) the simulation with the initial vortex having an isolated radial profile of potential temperature.

relatively distinct phases. Prior to deep convection initiation, the intensification is quite slow and dominated by baroclinic processes. When the deep convection commences, shortly after $t=120 \mathrm{~h}$, the first phase of more rapid deepening begins. This phase lasts approximately $18 \mathrm{~h}$ and is followed by an approximately $20-\mathrm{h}$ period of little or no deepening. After this lull, a longer period of deepening ensues. The characteristics of these two deepening phases are somewhat different from one another. As we will see, the earlier phase is associated with the MCV, and the latter is dominated by the larger, moist baroclinic system.

It is clear the diabatic heating is the dominant source of the eddy available potential energy $\left(G_{E}\right)$ during the first phase, which corresponds to the initial vortex development and intensification (as demonstrated in Fig. 6 ), and since diabatic heating is dominated by convection [see section $5 b(2)]$, it is evident the convection is primarily responsible for the deepening during this phase. Correspondingly, and continuing for some time thereafter, the baroclinic conversion term $\left(C_{A}\right)$ decreases somewhat. As it continues to decrease, the intensification, measured by surface pressure, becomes very slow. After $t=160 \mathrm{~h}$, the baroclinic conversion and diabatic conversion terms increase in tandem, and the minimum surface pressure decreases exponentially.

The rapid increase in the baroclinic conversion term, as well as the relatively large scale (approximately $2700-\mathrm{km}$ wavelength) suggests the excitation of the moist baroclinic system may be primarily responsible for the decrease in surface pressure. Using the characteristic wavelength of $2700 \mathrm{~km}$ (see Figs. 8 and 9) and a typical Rossby deformation radius for the basic state of approximately $850 \mathrm{~km}$, a dimensionless wavenumber of approximately 2 is obtained. Recalling the plot of growth rate as a function of wavenumber displayed in Fig. 1 of MM04, one finds that this wavenumber is near the peak of the growth rate versus wavenumber curve and corresponds to the most unstable moist baroclinic mode. On the other hand, the characteristic length scale of the simulated MCV, using the diameter of maximum winds, ranges from approximately $150 \mathrm{~km}$ upon initial development to $300 \mathrm{~km}$ at $t=170 \mathrm{~h}$. This falls within the cyclone wave regime, which is expected to grow more slowly than a $2700-\mathrm{km}$ wavelength wave.

\section{2) ISOLATED INITIAL VORTEX SIMULATION}

The isolated simulation was conducted with the initial temperature perturbation in the shape of the second derivative of the Gaussian radial profile for the surface potential temperature. This isolated vortex has the same $e$-folding radius of $300 \mathrm{~km}$ as in the control run and a maximum temperature perturbation of $3 \mathrm{~K}$. The isolated radial profile has a somewhat smaller horizontal scale than the control case, and consequently, the isolated vortex projects much less strongly onto the most unstable, moist baroclinic mode (approximately one-fourth the projection of the Gaussian vortex; see Fig. 2).

In the isolated simulation, deep convection did not initiate until $t=132 \mathrm{~h}$, approximately $6 \mathrm{~h}$ after initiation in the control simulation. By the end of the simulation, the overall system amplitude, measured in terms of surface pressure perturbation, is only about a third as deep as in the control simulation. This result is consistent with the smaller projection of the initial isolated vortex 
a
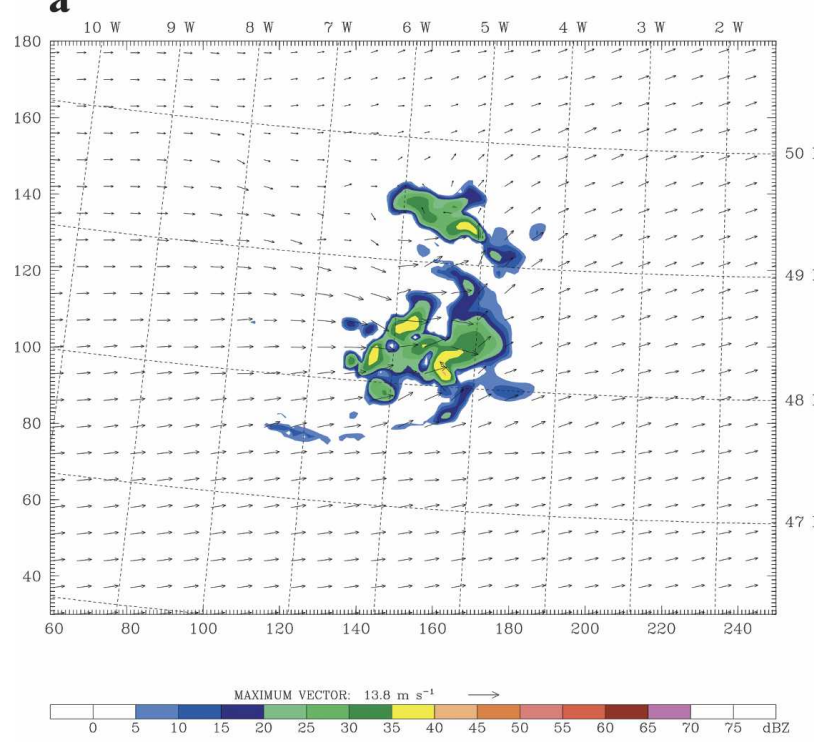

c

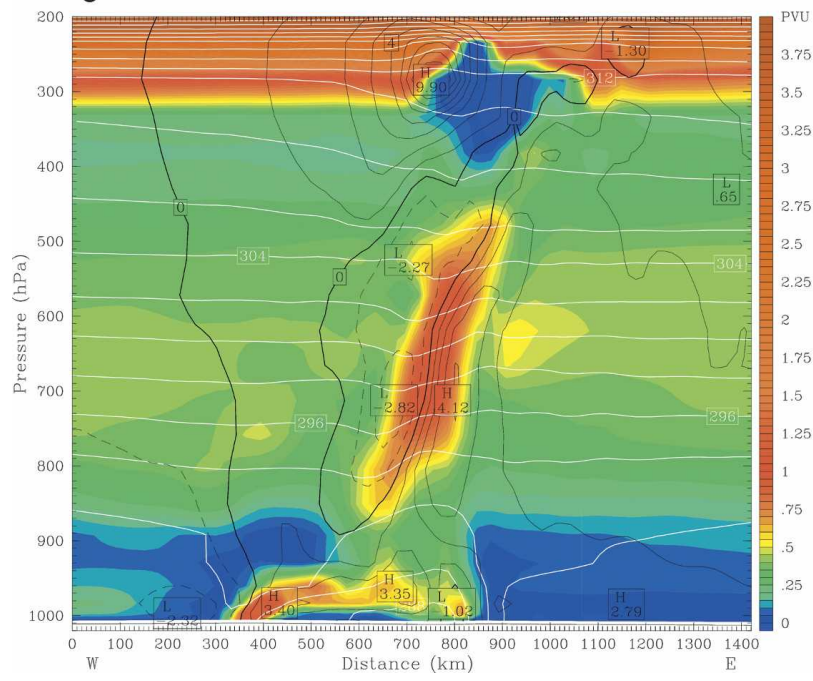

b
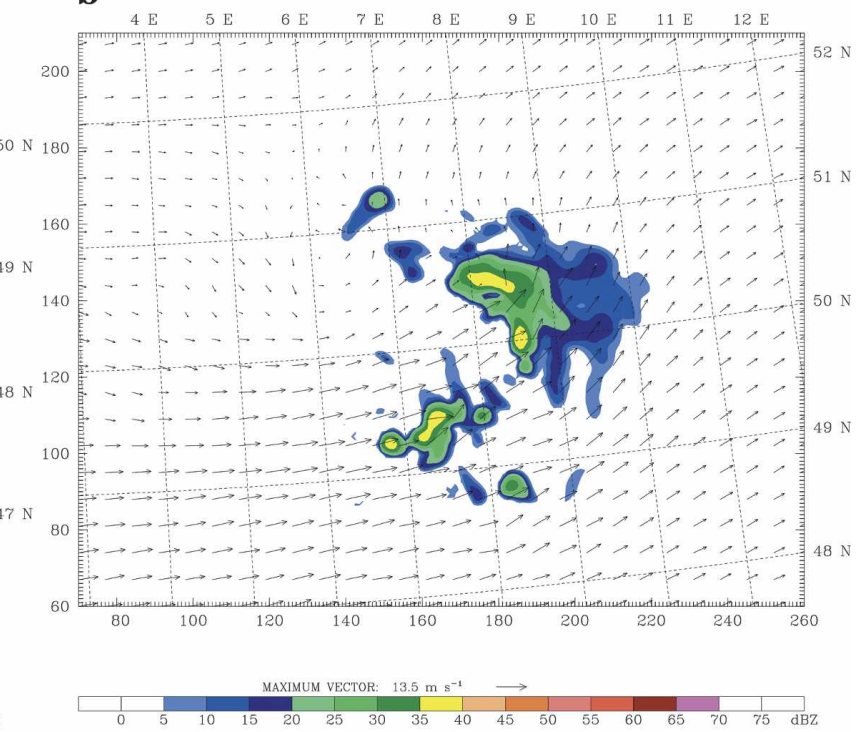

d

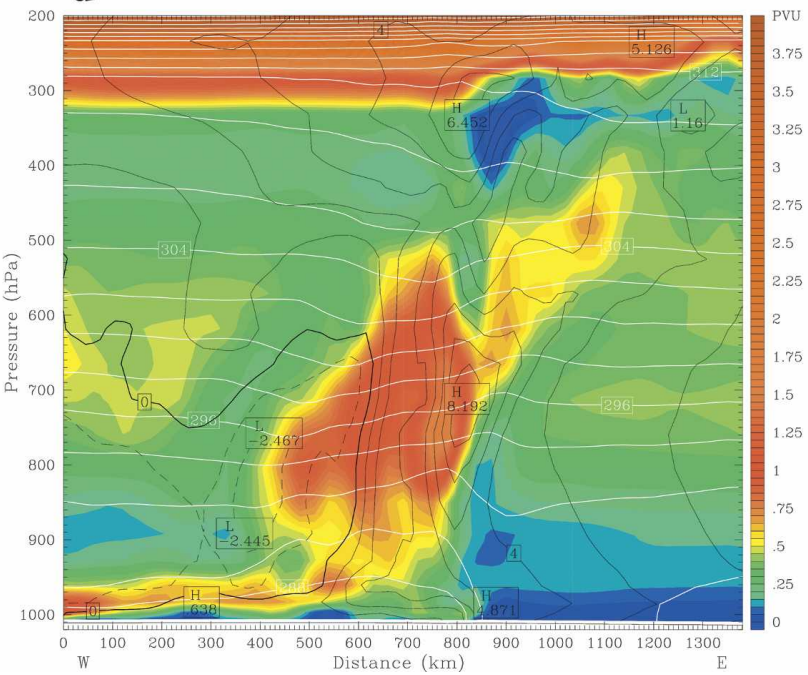

FIG. 12. Reflectivity and potential vorticity structure of the simulated DRV developing from an isolated vortex: 700-mb simulated reflectivity (dBZ; shading) on the 3.3-km grid at (a) $t=144 \mathrm{~h}$, approximately $12 \mathrm{~h}$ after initiation of deep convection and (b) $t=180$ $\mathrm{h}$, approximately $48 \mathrm{~h}$ after initiation; longitude-pressure cross section of the potential vorticity (PVU; shading), potential temperature (white contour lines; interval is $2 \mathrm{~K}$ ), and meridional velocity (black lines; contour interval is $1 \mathrm{~m} \mathrm{~s}^{-1}$; dashed lines for negative contours) on the $30-\mathrm{km}$ grid at (c) $t=144 \mathrm{~h}$ along $48.5^{\circ} \mathrm{N}$ from $17^{\circ} \mathrm{W}$ to $3^{\circ} \mathrm{E}$ and (d) $t=180 \mathrm{~h}$ along $50^{\circ} \mathrm{N}$ from $3^{\circ} \mathrm{W}$ to $17^{\circ} \mathrm{E}$. In (c) and (d), potential temperature and meridional velocity are averages over a $60-\mathrm{km}$ distance perpendicular to, and centered on, the cross section.

onto the most unstable baroclinic mode. Although convection develops and forms into a convective system, the horizontal extent of precipitation is not as great as it is in the control run (see Figs. 12a,b), and the convective system does not seem as well organized as in the control run. Nevertheless, the characteristic DRV structure is evident (Figs. 12c,d).

In terms of energetics, the isolated simulation (Fig. 11b) shows much weaker conversion of zonal available potential energy to eddy available potential energy $C_{A}$, as well as diabatic production of eddy available potential energy $G_{E}$. The smaller $G_{E}$ is a symptom of less extensive horizontal coverage of precipitation in the isolated simulation, and the smaller $C_{A}$ is consistent with the delayed growth of the most unstable moist baroclinic mode. Nevertheless, some of the behavior is qualitatively similar. Once deep convection initiates, surface pressure decreases, and the diabatic conversion $G_{E}$ increases and remains dominant over the baroclinic conversion term $C_{A}$. Through $t=190 \mathrm{~h}$, the baroclinic 
conversion term $C_{A}$ hovers around zero, but thereafter (not shown), it begins to increase, reflecting the growth of the moist baroclinic mode.

Overall, the comparisons between the control and isolated simulations indicate an interaction between the two scales (synoptic and mesoscale) in the overall weather system that develops. In the isolated run, the moist baroclinic growth, measured in terms of the time rate of change of the absolute value of the surface pressure perturbation, is slower than in the control run. Consequently, the advection of potential temperature and moisture is smaller than in the control simulation, resulting in slower destabilization and less convection. On the other hand, the MCV is contributing to the amplification of the system as a whole, but the contribution of the MCV is proportional to its size, indicated by the pressure drop that occurs immediately after convection initiates in both simulations; it is smaller in the isolated case than in the control case.

These results reflect interdependence between the MCV and the moist baroclinic disturbance in these simulations. Perhaps this interdependence between large and small scales is analogous to the interdependence between the low-level jets, which can be forced by large-scale topographic features, and the MCVs that frequently develop in association with such features, such as is the case in the BAMEX study area (Davis et al. 2004). As a further note regarding the scale interaction in these simulations, it is difficult to excite an $\mathrm{MCV} / \mathrm{DRV}$ in a near moist neutral baroclinic zone without exciting a synoptic-scale moist baroclinic disturbance. This is because almost any disturbance imposed on the flow has, in Fourier space, some projection onto this rapidly growing mode (see Fig. 2).

Essentially, the isolated vortex simulation is doubly penalized by relatively weak flow in the initial low-level vortex and lack of CAPE in the environment. With CAPE limited by the moist neutral profile in the background environment, a baroclinic system seems to be necessary to accomplish the destabilization required for the development of deep convection, and, once convection develops, to provide the continued influx of warm, moist air that facilitates the development of an MCV. In more typical MCV environments, larger CAPE may reduce the dependence on the baroclinic system. Investigation into this issue is ongoing with the analysis of a higher CAPE simulation, and initial results reveal a much stronger MCV, as shown in Fig. 13. Detailed results will be presented in a future study.

\section{Comparison with observational data (BAMEX)}

The purpose of BAMEX (Davis et al. 2004), conducted from 18 May to 7 July 2003, was to examine the life cycles of mesoscale convective systems. As pertains to the present study, the main objectives were to better understand the process of MCV formation within MCSs, the role of MCVs in initiating and modulating convection, and the feedback of convection onto $\mathrm{MCV}$ intensity.

Davis et al. (2004) presented an initial analysis of the observed BAMEX MCVs. Davis and Trier (2007) have performed a more detailed and systematic analysis of the temperature, velocity, and vorticity structure of the observed MCVs in BAMEX, which reveal that the DRV mechanism is present in those MCVs. Thus, rather than analyze specific BAMEX IOPs here, we have chosen to make an initial comparison that places the simulated vortices within the overall context of the BAMEX experiment. That is, we show that the simulated DRVs developed and sustained themselves in environments of CAPE and shear that are similar to those observed in BAMEX.

Table 2 shows a comparison among the vortex parameters of the control simulation, the CAPE simulation, and each of the five MCVs observed in BAMEX. The simulated CAPE refers to the CAPE in the basicstate environment at the latitude where the DRV developed. The CAPE in the BAMEX MCVs was calculated using two methods. In the first method, CAPE was calculated from the sounding nearest the point where an MCS was first observed. All soundings were 0000 UTC soundings regardless of when the MCS organized (although all MCSs organized around or shortly after 0000 UTC). In the second method, CAPE was calculated from the Eta Model analysis of CAPE at the point where the MCS was first defined [not necessarily the sounding location for (1), but always within $200 \mathrm{~km}$ ]. The maximum tangential velocity $V_{m}$ was estimated from Figs. 5 and 13 for the simulated vortices and from similar cross sections (not shown) calculated for the observed MCVs. The radius of maximum tangential velocity $R_{m}$ was taken as the radius of the maximum tangential wind. We computed the vertical shear in the layers from 1-4 and 1-8 km AGL in BAMEX by averaging all soundings within four quadrants, within $300 \mathrm{~km}$ of the vortex center, and then averaging the four quadrant averages. For the simulations, the indicated vertical shear is the shear of the background state. If analyzed in the same manner as the BAMEX MCVs, the shear in the simulated MCVs would perhaps be slightly less than what is indicated in Table 2. A comparison between vortex-centered shear and background shear would be an interesting analysis, for future work, to investigate the effects of the MCV and the convection in changing the shear.

Five separate MCVs were observed during the 

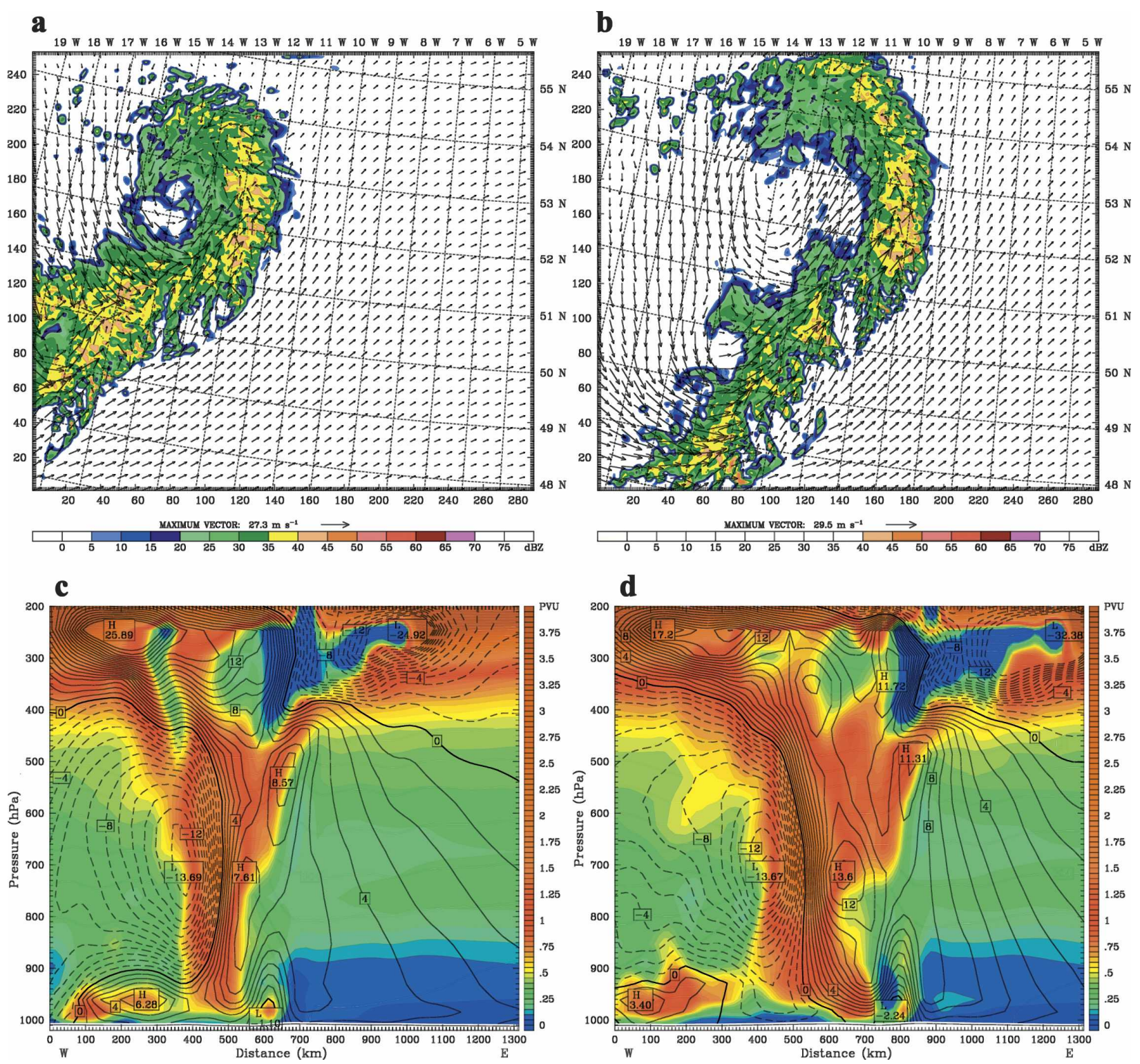

FIG. 13. Reflectivity and potential vorticity structure of the simulated DRV developing from an isolated vortex in an environment with approximately $2400 \mathrm{~J} \mathrm{~kg}^{-1}$ CAPE: 700-mb simulated reflectivity (dBZ; shading) on the 3.3-km grid at (a) $t=160 \mathrm{~h}$, approximately $8 \mathrm{~h}$ after initiation of deep convection and (b) $t=164 \mathrm{~h}$; longitude-pressure cross section of the potential vorticity (PVU; shading), potential temperature (white contour lines; interval is $2 \mathrm{~K}$ ), and meridional velocity (black lines; contour interval is $1 \mathrm{~m} \mathrm{~s}^{-1}$; dashed lines for negative contours) on the $30-\mathrm{km}$ grid along $52.5^{\circ} \mathrm{N}$ from $22^{\circ}$ to $2^{\circ} \mathrm{W}$ at (c) $t=160$ and (d) $t=164 \mathrm{~h}$. In (c) and (d), plotted values represent averages over a $300-\mathrm{km}$ distance perpendicular to, and centered on, the cross section.

BAMEX experiment, each in somewhat different backgrounds of CAPE and shear. It is therefore interesting that the tangential velocity $V_{m}$ of all the BAMEX MCVs was between 10 and $15 \mathrm{~m} \mathrm{~s}^{-1}$ and all had a radius of maximum winds $R_{m}$ between 100 and $150 \mathrm{~km}$ (see Table 2). The CAPE in the observed MCVs ranged between 300-1000 $\mathrm{J} \mathrm{kg}^{-1}$, estimated for IOP 1 , to around $2000 \mathrm{~J} \mathrm{~kg}^{-1}$ in IOPs 8 and 15 . The shear was strongest in IOPs 4 and 5 and was weakest in IOP 8 .
For the control simulation, the basic-state CAPE lies generally below the range encountered by MCVs in BAMEX, yet the maximum CAPE of approximately $600 \mathrm{~J} \mathrm{~kg}^{-1}$ is within the BAMEX range. The shear of the control simulation is well within the range of conditions encountered in the BAMEX IOPs. The maximum tangential velocity was, however, a bit weaker than in the observed MCVs. This result may be a reflection of the smaller CAPE generated in the back- 
TABLE 2. Properties of the simulated MCVs and MCVs observed in BAMEX, where $V_{m}$ is the maximum tangential velocity, $R_{m}$ is the radius of maximum tangential velocity, and $P_{m}$ is the pressure level of maximum tangential velocity.

\begin{tabular}{|c|c|c|c|c|c|c|c|}
\hline Simulation/IOP & Control & CAPE & 1 & 4 & 5 & 8 & 15 \\
\hline Date (2003) & None & None & 24 May & 2 June & 5 June & 11 June & 29 June \\
\hline$V_{m}\left(\mathrm{~m} \mathrm{~s}^{-1}\right)$ & 5 & 13 & 13 & 15 & 12 & 15 & 10 \\
\hline$R_{m}(\mathrm{~km})$ & 150 & 100 & 100 & 150 & 100 & 150 & 100 \\
\hline$P_{m}(\mathrm{mb})$ & 800 & 700 & 480 & 650 & 660 & 660 & 540 \\
\hline \multirow[t]{2}{*}{ CAPE $\left(\mathrm{J} \mathrm{kg}^{-1}\right)$} & 0 & 2400 & $300^{\mathrm{a}}$ & $600^{\mathrm{a}}$ & $1000^{\mathrm{a}}$ & $2000^{\mathrm{a}}$ & $2000+^{\mathrm{a}}$ \\
\hline & & & $1000^{\mathrm{b}}$ & $1000^{\mathrm{b}}$ & $2000^{\mathrm{b}}$ & $2000^{\mathrm{b}}$ & $1700^{\mathrm{b}}$ \\
\hline Shear, $1-4 \mathrm{~km}\left(\mathrm{~m} \mathrm{~s}^{-1}\right)$ & 4.5 & 4.5 & 12 & 14 & 12 & 2 & 8 \\
\hline Shear, $1-8 \mathrm{~km}\left(\mathrm{~m} \mathrm{~s}^{-1}\right)$ & 10.5 & 10.5 & 14 & 27 & 32 & 5 & 13 \\
\hline
\end{tabular}

${ }^{a}$ CAPE has been calculated from the sounding nearest the point where an MCS was first observed. All soundings are 0000 UTC soundings regardless of when the MCS organized (although all MCSs organized around or shortly after 0000 UTC).

${ }^{\mathrm{b}}$ CAPE has been calculated from the Eta Model analysis of CAPE at the point where the MCS was first defined (not necessarily the sounding location for 1, but always within $200 \mathrm{~km}$ ).

ground of a moist neutral environment and the correspondingly weaker diabatic heating in the midtroposphere. The differences between the control simulation and the BAMEX MCVs are consistent with the notion of a continuum between moist baroclinic, midlatitude cyclones in a stably stratified, strong shear environments at one end of the spectrum (as described in MM04 and MM05), MCVs in environments of CAPE and shear over continental areas in the middle, and tropical disturbances in environments of moderate CAPE and relatively weak shear at the other extreme.

The DRV of the CAPE simulation appears to lie in the middle of the BAMEX parameter space of CAPE and shear. Its CAPE was in a range consistent with the higher values observed for the BAMEX MCVs, and the shear fell nicely within the range observed in BAMEX. It is not surprising, therefore, that the maximum tangential velocity and radius of maximum winds was almost exactly in the middle of the range observed in BAMEX. This fact suggests that a simulated MCV growing in a background state of CAPE and shear, similar to the background environment in BAMEX, is governed by the same dynamic mechanisms responsible for the development and maintenance of DRVs. In terms of their radii of maximum winds and the tangential velocities, the MCVs in the CAPE simulation and the BAMEX cases are very similar, but the pressure level of maximum tangential velocity $P_{m}$ is at a somewhat greater value in the simulations than it is for the observed MCVs. It is unknown why this discrepancy exists.

The initial comparison, in terms of vortex parameters, motivates the need for further simulations that explore the range of parameters observed in BAMEX. Specifically, the shear encountered in BAMEX was both weaker and stronger than the background shear used in the simulations. Also, it may be interesting to perform simulations in backgrounds of stronger shear than was observed in BAMEX in order to determine the strength of shear necessary to prevent MCV formation and maintenance, regardless of the presence of sustained, deep moist convection.

\section{Conclusions}

Idealized, cloud-representing numerical simulations of a diabatic Rossby vortex (DRV) in a moist baroclinic, initially moist neutral atmosphere are used to examine the formation and maintenance of a midlevel circulation over a flat land surface during the warm season. The primary foci of this work are (i) to better understand how the presence of deep convection in a sheared environment can result in the spinup of a midlevel circulation and, once formed, how such a disturbance can interact with the environment in such a way as to trigger new convection in a location that is conducive to further vortex intensification (the DRV growth mechanism), resulting in a long-lived, growing disturbance; and (ii) compare the simulated DRV with atmospheric data on mesoscale convective vortices (MCVs) to test the hypothesis that the DRV growth and maintenance mechanism occurs in MCVs. Within this context, MCVs can be thought of as a subset of the more general DRV class of vortices. The main distinction between the two is that MCVs arise from mesoscale convective systems (MCSs) and are therefore generated only in convectively unstable environments, whereas DRVs also develop in convectively stable environments.

As is the case for DRV formation in a wintertime environment, a preconditioning phase is identified. Before deep convection and the formation of a midlevel circulation can occur, it is necessary to destabilize the atmosphere. This is accomplished here by a combina- 
tion of southerly moist advection and mesoscale lifting due to the interaction of a balanced, warm-core, surface-concentrated vortex and the sheared environment. A scale analysis on the control simulation shows that both processes are active in transporting moist static energy into the midtroposphere on the downshear side of the vortex. Subsequently, deep convection initiates, the convection organizes into a mesoscale convective system (MCS) and the characteristic structure of a DRV emerges: a positive PV anomaly in the lower troposphere and a negative anomaly in the upper troposphere, tilted downshear with height.

Consistent with the work of Raymond and Jiang (1990) and Jiang and Raymond (1995), it is found here that the DRV growth mechanism provides a useful paradigm for the maintenance of MCVs in the midlatitude warm season, but it is also proposed that the same paradigm applies to the MCV formation. The results of this study illustrate how a preexisting midlevel circulation, with zero interior PV anomaly initially, can interact with a sheared environment to focus convection in a region that is conducive to the further intensification of the vortex and the development of a PV anomaly structure that resembles that of a DRV. This occurs as follows: (i) the lower atmosphere is thermodynamically destabilized as high $\theta_{e}$ air is advected into the storm environment by the low-level cyclonic circulation associated with the vortex; (ii) forced ascent occurs as air parcels travel northward in the baroclinic atmosphere; (iii) new convective cells form in a region that consistently places the vortex in an area where rising motion is occurring; and (iv) the midlevel circulation intensifies as positive potential vorticity (PV) is generated. This process is self-sustaining as long as the environment is conducive. A dry run with the latent heating shut off after DRV development shows that the DRV becomes sheared and dissipates within a day of the removal of latent heating, although there is some remaining coherent structure below $500 \mathrm{mb}$ that dissipates more slowly. A simple scale analysis on the DRV also shows that the time scale associated with the tangential velocity is much longer than the shear time scale, thus ruling out a vortex resiliency mechanism for the vortex persistence. Both results confirm that the deep, moist convection is critical to the generation and maintenance of the DRV. Additionally, our analysis shows that the simulated convection is occurring in regions of balanced ascent, which provides strong evidence that the above mechanism is at work here.

To lend credence to the above idea, the control run DRV and the DRV simulated in a higher CAPE environment are placed within the context of the Bow Echo and MCV Experiment (BAMEX) field campaign. The control simulation DRV developed in an environment of weaker CAPE but similar shear compared to the MCVs in BAMEX. Its radius of maximum winds was within the range observed in BAMEX MCVs, but its tangential velocity was weaker, which could be a result of the smaller CAPE and weaker diabatic heating. The tangential velocity and radius of maximum winds for the DRV simulated in a background of $2400 \mathrm{~J} \mathrm{~kg}^{-1}$ CAPE were both within the range of values observed for BAMEX MCVs. Given these similar parameters between the DRV that develops in the simulation and the BAMEX MCVs, the comparison provides support for the proposed MCV formation and maintenance mechanism in terms of DRV dynamics. The results also show that a wider range of parameter space (in terms of CAPE and shear) must be utilized in the simulations to make a fuller comparison with atmospheric measurements.

An interesting aspect of the simulations is the apparent excitation of the fastest growing moist baroclinic mode that develops along with the emerging DRV at smaller scales. An additional simulation was conducted with an initial isolated vortex that had a smaller projection upon the moist baroclinic mode than the Gaussian vortex of the control simulation had. The results indicated reduced amplitude of the large-scale surface pressure perturbation throughout the simulation, and the DRV appeared to remain distinct from the moist baroclinic disturbance for a longer period during the simulation. However, precipitation coverage was smaller than in the control run, and the diabatic and baroclinic conversion to eddy available potential energy were both weaker, suggesting interdependence between the DRV/MCV and larger scales of atmospheric motion. Although this occurs between the DRV/MCV and the moist baroclinic disturbance in the simulations, the interaction may be analogous to that which occurs between large-scale, topographically forced circulations and the MCVs that develop within them. In either case, the flow associated with the larger system can also be considered balanced.

Finally, there are a number of simplifying assumptions made in this study that detract from the realism of these idealized simulations, foremost among them being the lack of a diurnal cycle. Future work will address this issue as well as to further examine what factors influence the presence or absence of a surface signature and the effects of higher CAPE and/or higher shear environments on the intensification and maintenance of the MCV.

Acknowledgments. This work was supported under National Science Foundation Grant ATM-0305412. We 
would also like to thank the three anonymous reviewers whose suggestions helped to greatly improve this manuscript.

\section{REFERENCES}

Cotton, W. R., M.-S. Lin, R. L. McAnelly, and C. J. Trembeck, 1989: A composite model of mesoscale convective complexes. Mon. Wea. Rev., 117, 765-783.

Davis, C. A., and M. L. Weisman, 1994: Balanced dynamics of mesoscale vortices produced in simulated convective systems. J. Atmos. Sci., 51, 2005-2030.

_ , and S. B. Trier, 2002: Cloud-resolving simulations of mesoscale vortex intensification and its effect on a serial mesoscale convective system. Mon. Wea. Rev., 130, 2839-2858.

$\longrightarrow$, and _ 2007: Mesoscale convective vortices observed during BAMEX. Part I: Kinematic and thermodynamic structure. Mon. Wea. Rev., in press.

— E. D. Grell, and M. A. Shapiro, 1996: The balanced dynamical nature of a rapidly intensifying oceanic cyclone. Mon. Wea. Rev., 124, 3-26.

— D. A. Ahijevych, and S. B. Trier, 2002: Detection and prediction of warm season midtropospheric vortices by the rapid update cycle. Mon. Wea. Rev., 130, 24-42.

- , and Coauthors, 2004: The bow echo and MCV experiment: Observations and opportunities. Bull. Amer. Meteor. Soc., 85, 1075-1093.

Eady, E. T., 1949: Long waves and cyclone waves. Tellus, 1, 33-52.

Fantini, M., 1995: Moist eady waves in a quasigeostrophic threedimensional model. J. Atmos. Sci., 52, 2473-2485.

- 2004: Baroclinic instability of a zero-PVE jet: Enhanced effects of moisture on the life cycle of midlatitude cyclones. $J$. Atmos. Sci., 61, 1296-1307.

_ mechanism of cyclogenesis in the Antarctic region. Tellus, 45A, 99-113.

— a moist environment. Quart. J. Roy. Meteor. Soc., 120, 10691084.

— layer. J. Atmos. Sci., 54, 2146-2154.

Fritsch, J. M., J. D. Murphy, and J. S. Kain, 1994: Warm core vortex amplification over land. J. Atmos. Sci., 51, 1780-1807.

Grell, G. A., J. Dudhia, and D. R. Stauffer, 1994: A description of the fifth-generation Penn State/NCAR mesoscale model (MM5). NCAR Tech. Note NCAR/TN-398+STR, 117 pp.

Gyakum, J. R., P. J. Roebber, and T. A. Bullock, 1992: The role of antecedent surface vorticity development as a conditioning process in explosive cyclone intensification. Mon. Wea. Rev., 120, 1465-1489.

Hertenstein, R. F. A., and W. H. Schubert, 1991: Potential vorticity anomalies associated with squall lines. Mon. Wea. Rev., 119, $1663-1672$.

Houze, R. A., Jr., 1997: Stratiform precipitation in regions of convection: A meteorological paradox? Bull. Amer. Meteor. Soc., 78, 2179-2196.

_- 2004: Mesoscale convective systems. Rev. Geophys., 42, RG4003, doi:10.1029/2004RG000150.

Jiang, H., and D. J. Raymond, 1995: Simulation of a mature me- soscale convective system using a nonlinear balance model. $J$. Atmos. Sci., 52, 161-175.

Johnson, R. H., S. Chen, and J. J. Toth, 1989: Circulations associated with a mature-to-decaying midlatitude mesoscale convective system. Part I: Surface features-Heat bursts and mesolow development. Mon. Wea. Rev., 117, 942-959.

Knievel, J. C., D. S. Nolan, and J. P. Kossin, 2004: Imbalance in a mesoscale vortex within a midlatitude, continental mesoscale convective system. J. Atmos. Sci., 61, 1827-1832.

Lapeyre, G., and I. M. Held, 2004: The role of moisture in the dynamics and energetics of turbulent baroclinic eddies. J. Atmos. Sci., 61, 1693-1710.

Mak, M., 1994: Cyclogenesis in a conditionally unstable moist baroclinic atmosphere. Tellus, 46A, 14-33.

Menard, R. D., and J. M. Fritsch, 1989: A mesoscale convective complex-generated inertially stable warm core vortex. Mon. Wea. Rev., 117, 1237-1261.

Montgomery, M. T., and B. F. Farrell, 1991: Moist surface frontogenesis associated with interior potential vorticity anomalies in a semigeostrophic model. J. Atmos. Sci., 48, 343-367.

—, and —, 1992: Polar low dynamics. J. Atmos. Sci., 49, 2484 2505.

_ and R. Kallenbach, 1997: A theory for vortex Rossby waves and its application to spiral bands and intensity changes in hurricanes. Quart. J. Roy. Meteor. Soc., 123, 435-465.

Moore, R. W., and M. T. Montgomery, 2004: Reexamining the dynamics of short-scale, diabatic Rossby waves and their role in midlatitude moist cyclogenesis. J. Atmos. Sci., 61, 754-768.

— and 2005: Analysis of an idealized, three-dimensional diabatic Rossby vortex: A coherent structure of the moist baroclinic atmosphere. J. Atmos. Sci., 62, 2703-2725.

Norquist, D. C., E. E. Recker, and R. J. Reed, 1977: The energetics of African wave disturbances as observed during Phase III of GATE. Mon. Wea. Rev., 105, 334-342.

Olsson, P. Q., and W. R. Cotton, 1997a: Balanced and unbalanced circulations in a primitive equation simulation of a midlatitude MCC. Part I: The numerical simulation. J. Atmos. Sci., $\mathbf{5 4 ,} 457-478$.

$\longrightarrow$, and $ـ$ 1997b: Balanced and unbalanced circulations in a primitive equation simulation of a midlatitude MCC. Part II: Analysis of balance. J. Atmos. Sci., 54, 479-497.

Parker, D. J., and A. J. Thorpe, 1995: Conditional convective heating in a baroclinic atmosphere: A model of convective frontogenesis. J. Atmos. Sci., 52, 1699-1711.

Raymond, D. J., and H. Jiang, 1990: A theory for long-lived mesoscale convective systems. J. Atmos. Sci., 47, 3067-3077.

Reasor, P. D., M. T. Montgomery, and L. D. Grasso, 2004: A new look at the problem of tropical cyclones in vertical shear flow: Vortex resiliency. J. Atmos. Sci., 61, 3-22.

Schecter, D. A., M. T. Montgomery, and P. D. Reasor, 2002: A theory for the vertical alignment of a quasigeostrophic vortex. J. Atmos. Sci., 59, 150-168.

Snyder, C., and R. S. Lindzen, 1991: Quasi-geostrophic waveCISK in an unbounded baroclinic shear. J. Atmos. Sci., 48, $76-86$.

Trier, S. B., and C. A. Davis, 2002: Influence of balanced motions on heavy precipitation within a long-lived convectively generated vortex. Mon. Wea. Rev., 130, 877-899.

$\longrightarrow,-$, and J. D. Tuttle, 2000a: Long-lived mesoconvective 
vortices and their environment. Part I: Observations from the central United States during the 1998 warm season. Mon. Wea. Rev., 128, 3376-3395.

- _ - and W. C. Skamarock, 2000b: Long-lived mesoconvective vortices and their environment. Part II: Induced thermodynamic destabilization in idealized simulations. Mon. Wea. Rev., 128, 3396-3412.

Weisman, M. L., and C. A. Davis, 1998: Mechanisms for the gen- eration of mesoscale vortices within quasi-linear convective systems. J. Atmos. Sci., 55, 2603-2622.

Wernli, H., S. Dirren, M. A. Liniger, and M. Zillig, 2002: Dynamical aspects of the life cycle of the winter storm "Lothar" (24-26 December 1999). Quart. J. Roy. Meteor. Soc., 128, 405-429.

Whitaker, J. S., and C. A. Davis, 1994: Cyclogenesis in a saturated environment. J. Atmos. Sci., 51, 889-907. 